\title{
DIVORCIO ENTRE CÓNYUGES DEL MISMO SEXO COMO PARADIGMA DE LA INELUDIBLE INCORPORACIÓN DEL FORUM NECESSITATIS AL REGLAMENTO BRUSELAS II BIS
}

\author{
MARÍA ÁNGELES SÁNCHEZ JIMÉNEZ ${ }^{1}$ \\ Universidad de Murcia \\ m.angeles@um.es
}

Cómo citar/Citation

Sánchez Jiménez, M. A. (2019).

Divorcio entre cónyuges del mismo sexo como paradigma de la ineludible incorporación del forum necessitatis al reglamento Bruselas II bis. Revista de Derecho Comunitario Europeo, 63, 407-448.

https://doi.org/10.18042/cepc/rdce.63.02

\section{Resumen}

El presente trabajo aborda el problema que puede presentar el divorcio entre cónyuges del mismo sexo, con carácter instrumental respecto del doble objetivo que pretende. El primero, mostrar que la incorporación del forum necessitatis al Reglamento 2201/2003 es una cuestión tan necesaria como, actualmente, ineludible, y el segundo, aportar una propuesta para la articulación de este foro sobre la base del que recogen los nuevos reglamentos (UE) y, en particular, los más recientes en materia de regímenes económicos matrimoniales y sobre los efectos patrimoniales de las uniones registradas.

1 Profesora titular de Derecho Internacional Privado, Universidad de Murcia. El presente trabajo se enmarca en el Proyecto $\mathrm{I}+\mathrm{D}$ «Movilidad internacional de personas: El impacto jurídico-social en España y en la UE de la adquisición de la nacionalidad española por la población inmigrante» (DER2016-75573-R), concedido por el Ministerio de Economía, Industria y Competitividad de España. 


\title{
Palabras clave
}

Forum necessitatis; Reglamento 2201/2003; divorcio; cónyuges del mismo sexo; denegación de justicia.

\section{DIVORCE BETWEEN SAME SEX SPOUSES AS A PARADIGM OF THE \\ UNAVOIDABLE INCORPORATION OF THE FORUM NECESSITATIS TO THE "BRUSSELS II BIS" REGULATION}

\begin{abstract}
The aim of this paper is to tackle the problem of same sex spouses divorces with instrumental nature, with regard to the double objective that it pursues. The first purpose is to show that the incorporation of the forum necessitatis to the 2201/2003 Regulation is a matter as necessary as unavoidable nowadays. The second one is to make a proposal for the articulation of this forum on the basis of the one provided by the new EU Regulations and, particularly, by the most recent in matters of matrimonial property regimes, and the on property consequences of registered partnerships.
\end{abstract}

\section{Keywords}

Forum necessitates; Regulation 2201/2003; Divorce; Same sex spouses; Denial of justice.

\section{DIVORCE ENTRE CONJOINTS DE MÊME SEXE COMME LE PARADIGME DE L'INCONTOURNABLE INCORPORATION DU FORUM NECESSITATIS AU RÈGLEMENT «BRUXELLES II BIS»}

\section{Résumé}

Le présent document aborde le problème que le divorce entre conjoints de même sexe peut poser avec un caractère instrumental concernant le double objectif prétendu. Le premier est de montrer que l'incorporation du forum necessitatis au règlement «Bruxelles II bis» est une question aussi nécessaire que, actuellement, incontournable et, le second, est d'apporter une proposition pour l'articulation de ce forum sur la base des apports des nouveaux règlements européens et, particulièrement, des plus récent en matière de régimes matrimoniaux et du Règlement en matière d'effets patrimoniaux des partenariats enregistrés.

\section{Mots clés}

Forum necessitatis; Règlement 2201/2003; Divorce; Conjoints de même sexe; Déni de justice. 


\section{SUMARIO}

I. INTRODUCCIÓN. II. LA PERSPECTIVA ACTUAL. EL REGLAMENTO BRUSELAS II bis ANTE EL PROBLEMA DE LA DENEGACIÓN DE JUSTICIA: 1. Divorcio entre cónyuges del mismo sexo. Delimitación de las «situaciones problemáticas». 2. De la operatividad de los foros internos a la articulación del forum necessitatis. 3. El forum necessitatis como vía de solución. III. PARÁMETROS PARA LA ARTICULACIÓN DEL FORUM NECESSITATIS EN EL REGLAMENTO BRUSELAS II bis: 1. Especial consideración de los reglamentos (UE) 2016/1103 y 2016/1 104. 2. La inhibición del órgano jurisdiccional como clave fundamental de la solución. 3. Presupuestos para la operatividad del forum necessitatis. IV. CONCLUSIONES. BIBLIOGRAFía.

\section{INTRODUCCIÓN}

El presente análisis se centra en la necesaria incorporación del forum necessitatis al Reglamento 2201/20032, también conocido como Reglamento Bruselas II bis (a partir de ahora RBIIbis). Con esta finalidad, su desarrollo se aborda a través del problema de la denegación de justicia que se puede generar en el caso de divorcio (entendido por referencia a los supuestos que se comprenden en la relajación o disolución del vínculo matrimonial) entre cónyuges del mismo sexo, cuando la competencia judicial venga atribuida a los órganos jurisdiccionales de un Estado miembro en virtud de los foros del RBIIbis. Un problema

2 Reglamento 2201/2003, de 27 de noviembre de 2003, relativo a la competencia, el reconocimiento y la ejecución de resoluciones judiciales en materia matrimonial y de responsabilidad parental, por el que se deroga el Reglamento (CE) 1347/2000 (DO L 338, de 23 de diciembre de 2003). Es necesario indicar que, durante la fase de corrección de las pruebas de imprenta del presente trabajo, ha sido publicado el nuevo Reglamento (UE) 2019/1111, de 25 de junio de 2019 (DOUE L 178, de 2 de julio de 2019), elaborado para la modificación del Reglamento 2201/2003. No obstante, la derogación de este último no será efectiva hasta el 1 de agosto de 2022, como establece en su art. 104, aunque su entrada en vigor tenga lugar a los veinte días de su publicación (art. 105). En todo caso, es importante señalar que a los efectos del presente trabajo, el nuevo reglamento no afecta a la trascendencia del objeto que aborda, ya que las normas de compentencia, en las que este análisis se integra, apenas han sido objeto de modificación por este nuevo texto. 
que, por su indudable trascendencia y especial gravedad, es el evidente reflejo («paradigma») de la necesidad, que incluso podría calificarse de urgente, de una solución inminente. Esta es la razón de que el problema señalado se considere a lo largo del presente análisis con el carácter instrumental necesario, a la vez que esencial, en tanto que configura el hilo conductor sobre el que se articula el doble objetivo sobre el que gravitan, respectivamente, los dos principales apartados que se distinguen a efectos de sistemática.

El primero de ellos, que se aborda en el apartado II, pretende mostrar que la incorporación del forum necessitatis al RBIIbis es una cuestión tan trascendente como ineludible. Con este objetivo, es preciso comenzar por delimitar las que se denominan «situaciones problemáticas», como centro neurálgico por el que discurre el desarrollo del planteamiento del problema, en las que se plantea la denegación de justicia por referencia al caso de divorcio entre cónyuges del mismo sexo. Sobre esta base se aborda posteriormente la situación actual, que exige plantear el alcance y las consecuencias de la operatividad de los foros internos de competencia (en virtud de lo previsto en sus arts. 6 y 7), como vía de solución de aquellas «situaciones problemáticas». Las consecuencias constatadas mediante este análisis ofrecen evidentes argumentos para manifestar la relevancia de la articulación del forum necessitatis en el RBIIbis que, además, estaría en línea con los reglamentos de la UE que se ocupan de las normas de derecho internacional privado relativas a las relaciones familiares de carácter internacional.

No deja de ser llamativo que, entre estos Textos reglamentarios, el único que no recoge este foro es el RBIIbis, un hecho que puede alegarse como argumento para su incorporación, aún más evidente si se considera que, de aquellos, se pueden extraer los elementos esenciales para su articulación. En este sentido, el segundo objetivo del trabajo, que se aborda en su apartado III, responde a la finalidad de delimitar los aspectos a los que ha de ajustarse la articulación del forum necessitatis en el RBIIbis sobre la base de las respuestas que ofrecen los reglamentos de la UE, más concretamente a partir de las ofrecidas por los más recientes en materia de regímenes económicos matrimoniales y sobre los efectos patrimoniales de las uniones registradas. La causa de su específica consideración se encuentra, por las razones que en su momento se exponen, en el paralelismo que se constata entre el planteamiento (origen y motivos: causa) del problema de la denegación de justicia que puede generarse en el contexto de estos reglamentos, respecto del que se constata en las «situaciones problemáticas» que configuran nuestro objeto. El desarrollo de este análisis permite llegar a las conclusiones finales del trabajo, articuladas de acuerdo con el doble objetivo que persigue (apartado IV). 


\section{LA PERSPECTIVA ACTUAL. EL REGLAMENTO BRUSELAS II BIS ANTE EL PROBLEMA DE LA DENEGACIÓN DE JUSTICIA}

Con el objetivo de considerar la actual respuesta que ofrece el RBIIbis a las situaciones de denegación de justicia, el punto de partida exige la delimitación de las que configuran el eje esencial por el que discurre el desarrollo del presente análisis.

\section{DIVORCIO ENTRE CÓNYUGES DEL MISMO SEXO. DELIMITACIÓN DE LAS «SITUACIONES PROBLEMÁTICAS»}

Del origen y causa del problema. El problema que puede generarse en el caso de divorcio entre cónyuges del mismo sexo en el ámbito de la UE tiene su causa en la diversidad que existe entre los Estados miembros respecto a la reglamentación de la "validez del matrimonio» ${ }^{3}$. Un concepto que no se presenta unificado por el RBIIbis, como tampoco por el Reglamento (UE) 1259/2010 (también conocido como reglamento Roma III, a partir de ahora RRIII) $)^{4}$. La conexión de esta diversidad con la admisión (o no) del matrimonio entre personas del mismo sexo presenta directa incidencia llegado el momento de su divorcio, particularmente en el caso en que resulten competentes, en virtud del RBIIbis, los órganos jurisdiccionales de un Estado miembro que no admita su validez ${ }^{5}$. Se trata de una situación

3 Siguiendo a González Beilfuss (2004b: 150) se puede afirmar que, «consecuencia de la integración del DIPr en el Derecho comunitario y de la recíproca influencia de los distintos ámbitos de éste, la diversidad de concepciones respecto del matrimonio entre personas del mismo sexo motiva que el consenso europeo respecto a la noción de matrimonio se haya visto alterado tras la introducción del matrimonio homosexual, que pone de manifiesto la necesidad de un proceso de convergencia de los Derechos materiales».

4 Reglamento $1259 / 2010$, de 20 de diciembre de 2010, por el que se establece una cooperación reforzada en el ámbito de la ley aplicable al divorcio y a la separación judicial (DO L 343, de 29 de diciembre de 2010).

5 La aplicación del RBIIbis a los matrimonios entre personas del mismo sexo suscitó, en principio, cierta polémica doctrinal como fue destacada por Mosconi (2005: 305) y González Beilfuss, (2004a: 190). Al respecto, Borrás Rodríguez (2013: 11) señalaba que el Reglamento no prejuzga (ni tampoco el Informe Borrás), deliberadamente, la cuestión de su aplicación al matrimonio tradicional o al matrimonio homosexual. También Soto Moya (2013b: 596) se refiere a la postura enfrentada, realizando un análisis de las razones a favor de su admisión. En todo caso, a partir de la aprobación del RRIII no parece que pueda quedar duda alguna de la aplicación del RBIIbis para la determinación de la competencia respecto de los matrimonios entre personas del 
que puede plantearse, tanto si estos órganos jurisdiccionales pertenecen a un Estado miembro no participante del mecanismo de la «cooperación reforzada» en que se basa el RRIII como, lo que es más grave, si pertenecen a un «Estado miembro participante». Una solución más coherente con el objetivo de sus normas hubiera permitido la unificación del concepto de «validez del matrimonio", que hubiera sido necesaria en un reglamento regulador de la ley aplicable a la separación y divorcio ${ }^{6}$. Ante esta ausencia ${ }^{7}$, la opción de su

mismo sexo, pues, de hecho, puede considerarse que el art. 13 del RRIII presupone dicha aplicación, ya que, precisamente, sobre esta base puede entenderse que el objeto de la regulación de este precepto sea permitir que no se pronuncie una sentencia de divorcio por parte de los órganos jurisdiccionales competentes, cuyo ordenamiento no reconociera este matrimonio. Una extensa consideración en este sentido realiza Gruber (2013: 201) y Maseda Rodríguez (2018:207).

6 Desde el origen de este texto, era destacada la necesidad de esta unificación defendiendo una amplitud de la concepción. En ese sentido Franzina (2011: 101), al defender un concepto de "matrimonio" suficientemente amplio para acoger el conjunto de las relaciones; Orejudo Prieto de los Mozos (2012: 3), quien, considerando las diferencias existentes entre los Estados miembros sobre la propia concepción del matrimonio, señala que la unificación de la ley aplicable a la nulidad (validez) hubiera resultado quizá aún más necesaria que la del divorcio o separación. Por su parte, Abarca Junco (2013: 56) defiende que la cuestión ha de centrarse en el término "validez», que no aclara el Reglamento, ya que el hecho de que se hable de validez y no de reconocimiento permite entender que se trata de una vía abierta a los tribunales de aquellos países que no reconocen diversos tipos de matrimonio, de forma que a través de esta posibilidad pueden considerar su validez de acuerdo a su derecho interno. En el mismo sentido Hammje (2011: 301-302) indica que la exclusión de la cuestión relativa a la validez de un matrimonio del ámbito del RRIII presenta, entre otros efectos, el resultado de una "cierta esquizofrenia» en tanto el Reglamento quiere imponer, a través de la unificación conflictual, una concepción europea del divorcio, y por tanto del matrimonio, al mismo tiempo que salvaguarda plenamente las diversidades nacionales. También realiza un análisis específico y amplio sobre este aspecto Álvarez de Toledo Quintana (2013: 140).

7 Frente a la ausencia del concepto común sobre la «validez del matrimonio» se han aportado posibilidades que hubieran podido ser consideradas, esencialmente la que hubiera podido venir mediante el reconocimiento del matrimonio por referencia al país de celebración. En este sentido Devers y Farge (2012: 3), Orejudo Prieto de los Mozos (2002: 250), Esteban de la Rosa (2009: 201) y Arenas García (2004: 206), quien defiende la obligación de los Estados miembros de admitir los matrimonios válidamente celebrados en cualquier otro Estado miembro sobre la base al art. 21 del TUE. En cualquier caso, lo cierto es que las dificultades también están presentes cuando la solución para la unificación se proponga a través de la obligación de los Estados miembros de admitir la validez del matrimonio celebrado en los demás Estados 
art. 13 por la vía de la salvaguarda de la diversidad de las concepciones del foro supone realmente la priorización de la concepción restrictiva, al permitir que no se dicte una sentencia de divorcio respecto de un matrimonio cuya validez no sea reconocida por el «Estado miembro participante» al que pertenecen los órganos jurisdiccionales competentes, en el sentido, como aclara el considerando (26) que lo interpreta, de que ese matrimonio no exista según la ley de dicho Estado ${ }^{8}$.

Este precepto supone el reconocimiento de una ruptura en la aplicación del propio texto reglamentario, que introduce una fragmentación entre los «Estados miembros participantes». Sus consecuencias, teniendo en cuenta los supuestos que subyacen en la diversidad de las legislaciones a la que se refiere, son esenciales en relación a los matrimonios entre personas del mismo sexo?. La diversidad, en lo que respecta a su validez, existe de forma paralela cuando se trata de su divorcio, y aquí radica la trascendencia de este precepto, por su pretensión de evitar cualquier riesgo. El resultado que implica la quiebra en la aplicación del Reglamento puede presentar directa incidencia en la misma posibilidad de acceso al divorcio cuando, en virtud del RBIIbis, la competencia quede atribuida a los tribunales de alguno de los «Estados miembros participantes» que

miembros. Muestra de ello es que los reglamentos (UE) más recientes no proceden tampoco a un concepto unánime cuando existe diversidad de tratamiento entre los Estados miembros, ni tampoco abren la vía para que estos puedan partir del reconocimiento de la situación creada en otro distinto. Particularmente claro es, en este sentido, el Reglamento 2016/1104, relativo a las uniones registradas, que ni aporta un concepto ni establece obligación alguna para los Estados miembros de admitir la validez de la unión registrada en otro Estado miembro. Por el contrario, como se analiza posteriormente, este texto recoge expresamente la protección de la diversidad de las legislaciones, de forma similar a la que resulta del art. 13 del RRIII.

8 Un aspecto que refleja, como afirma Guzmán Zapater (2012: 528), una «timidez» en la búsqueda del compromiso al considerar que, en este punto, el art. 13 ofrece su faceta más política. Realmente, cabe destacar con Rigaux (2000: 647) la perspectiva conservadora de este precepto en un contexto en el que los Estados miembros divergen en los conceptos básicos del derecho de familia.

9 En España admitidos por la Ley 13/2005, de 1 de julio, por la que se modifica el Código Civil en materia de derecho a contraer matrimonio (BOE, 157, de 2 julio 2005). La celebración de los matrimonios entre personas del mismo sexo presenta una evidente fuerza atractiva en España, consecuencia de la doctrina de la DGRN en la Resolución-Circular de 29 de julio de 2005 (BOE, 188, de 8 agosto de 2005). Una postura que suscita diversas opiniones doctrinales como destacan Arenas García (2005: 351); Díaz Fraile (2006: 1); García Rubio (2005: 1); Quiñones Escámez (2005: 1172); Orejudo Prieto de los Mozos (2006: 299); Calvo y Carrascosa (2007: 1149); Zabalo y Diago (2007: 245); Álvarez González (2007: 1531), o Rodríguez Vázquez (2008: 913). 
no reconozca la validez de dicho matrimonio, dado que «no quedan obligados a pronunciar una sentencia de divorcio» ${ }^{10}$. De llegarse a este caso, la denegación de justicia ${ }^{11} \mathrm{y}$, con ella, la vulneración del derecho a la tutela judicial, que puede generarse en este espacio judicial de libertad y seguridad, es el evidente reflejo del problema que se aborda a lo largo del presente trabajo, motivando la especial consideración de estos casos, a los que, a partir de ahora, se identifican con la denominación de las «situaciones problemáticas».

Es particularmente grave que el RRIII introdujera este precepto sin advertir (o, de haberlo hecho, aún peor) esta consecuencia, ya que, de otro modo, hubiera previsto una solución paralela, integrada en sede de competencia donde el problema se materializa, mediante la articulación de un forum necessitatis en el propio RBIIbis.

La crónica de una solución mutilada. La articulación del forum necessitatis se incorporaba en las normas de competencia de la "propuesta RRIII» mediante la Resolución del Parlamento Europeo de $2008^{12}$. No obstante, la continuación de los trabajos posteriores, con el consecuente abandono de la misma, provocó, de forma paralela, el «olvido» de este foro. En todo caso, la

10 Como señala Joubert (2013: 623), en este caso no se trata de la aplicación de la ley del foro, sino que el precepto reconoce la posibilidad de no dictar una sentencia de divorcio, una facultad de optout. Siguiendo a Guzmán Zapater (2012: 533) cabe indicar que la singularidad de esta disposición se compadece mal con los objetivos típicos de un área de integración jurídica, aportando una solución inédita en correspondencia con la explosión de las estructuras familiares. De acuerdo con estas consideraciones plantea la cuestión de la compatibilidad de este precepto con la normativa europea en materia de derechos fundamentales. Como ha señalado Gruber (2013: 65), los efectos son esenciales en cuanto impide la continuidad de las relaciones jurídicas en el espacio comunitario, aspecto al que también se refiere Corneloup (2013: 508).

Sobre la noción de «denegación de justicia», los supuestos en que se pueden considerar el alcance de la misma así como una exhaustiva consideración sobre los distintos aspectos relativos al forum necessitatis se encuentran en el análisis realizado por Fernández Rozas (2017). Como indica, «el derecho de acceso a la justicia implica que no se produzcan supuestos de rechazo a la misma, con lo cual la noción de "denegación de justicia" se vincula directamente a la tutela judicial efectiva». También es destacable la vinculación que pone de manifiesto entre la ausencia de tutela judicial efectiva y foro de necesidad (párrs. núms. 2 y 6 , respectivamente).

12 Resolución legislativa del Parlamento Europeo, de 21 de octubre de 2008 (P6_TA (2008) 0502), «sobre la propuesta de Reglamento del Consejo por el que se modifica el Reglamento (CE) núm. 2201/2003 por lo que se refiere a la competencia y se introducen normas relativas a la ley aplicable en materia matrimonial (COM(2006) 0399 - C6-0305/2006 - 2006/0135(CNS)», DO, C 15E, de 21 enero de 2010. 
protección de la disparidad de las legislaciones sobre la validez del matrimonio no fue objeto de consideración en la siguiente propuesta de reglamento de 2010, ya referida únicamente a las normas conflictuales ${ }^{13}$. La situación, sin embargo, daba un salto cualitativo cuando el Parlamento Europeo, en la resolución sobre esta última, introdujo, mediante su enmienda 45, un art. 7 bis (nuevo) cuyo contenido pasaba a integrarse en el actual art. 13 del RRIII ${ }^{14}$. El problema es que este texto no tuvo en cuenta, y aquí radica el aspecto esencial, que también el Parlamento, en esta misma resolución (punto tercero), pedía a la Comisión que presentara «una propuesta de modificación del Reglamento (CE) 2201/2003, limitada a la adición de una cláusula sobre el forum necessitatis, como cuestión de suma urgencia antes de la prometida revisión general del Reglamento» ${ }^{15}$. Una evidente muestra de la trascendencia (y «urgencia») de introducir este foro en las normas de competencia que, sin embargo, no llegaba finalmente a plasmarse en el RBIIbis, continuando, en su lugar, con la remisión a los foros internos de los Estados miembros.

Con independencia de la consideración del contenido con el que se articulaba el forum necessitatis ${ }^{16}$, lo que ahora interesa destacar es que esta

13 Se trata de la «Propuesta de Reglamento del Consejo (UE) por el que se establece una cooperación reforzada en el ámbito de la ley aplicable al divorcio y a la separación judicial» (COM (2010) 105 final).

14 «Resolución legislativa del Parlamento Europeo, de 15 de diciembre de 2010, sobre la Propuesta de Reglamento del Consejo por el que se establece una cooperación reforzada en el ámbito de la ley aplicable al divorcio y a la separación judicial» (P7 TA(2010)0477, DO C 169E, de 15 junio 2012). El nuevo art. 7 bis que introducía en su enmienda (45), rubricado «Diferencias en las legislaciones nacionales», señalaba que «ninguna de las disposiciones del presente Reglamento obligará a los órganos jurisdiccionales de un Estado miembro participante cuya ley no prevea el divorcio o no considere el matrimonio de que se trate válido a los efectos de un proceso de divorcio a pronunciar una sentencia de divorcio en virtud de la aplicación del presente Reglamento». Además, con el objeto de interpretar este nuevo precepto, la resolución del Parlamento introducía la enmienda 24 para insertar un nuevo considerando 21 bis que, del mismo modo, pasa a integrarse en el RRIII [considerando 26].

15 Una solicitud demandada por el Consejo a la Comisión (Documento del Consejo, de 26 de noviembre de 2010, 17046/10, JUSTCIV 214, JAI 1008).

16 No puede valorarse positivamente este foro de acuerdo con la articulación ofrecida por el Parlamento Europeo, en la que, además del criterio del lugar de celebración del matrimonio, recogía, de forma alternativa, el foro de la nacionalidad de uno de los cónyuges en un Estado miembro. Una articulación merecedora de evidentes críticas —Sánchez Jiménez (2013a: 168)—, tanto por la alternatividad con la que configura los foros que recoge, como por el foro de la nacionalidad de uno de los cónyuges, que presenta los resultados de un foro exorbitante. 
solución quedó únicamente planteada y, a pesar de la necesidad que alegaba el Parlamento, no llegó a prosperar. Se trata de una muestra, entre otras, de la descoordinación entre estos dos reglamentos comunitarios, cuya repercusión incide directamente en los ciudadanos ${ }^{17}$.

\section{DE LA OPERATIVIDAD DE LOS FOROS INTERNOS A LA ARTICULACIÓN DEL FORUM NECESSITATIS}

Expuestos el problema de la denegación de justicia y las «situaciones problemáticas» por las que discurre nuestro desarrollo, la cuestión inmediata es el planteamiento de la solución que pueda aportar el RBIIbis. En este sentido, siendo la única posibilidad la operatividad de los foros internos que permiten sus arts. 6 y 7, la respuesta a la cuestión planteada exige abordar el alcance del resultado que presenta esta vía para resolverlo.

El punto de partida. El punto de partida para la respuesta exige considerar el alcance de la operatividad de los foros internos de los Estados miembros, de acuerdo con la interpretación del TJUE en su conocida sentencia en el asunto Sundelind sobre los arts. 6 y 7 del RBIIbis ${ }^{18}$. En ella vino a establecer que los órganos jurisdiccionales de un Estado miembro no pueden basar su competencia en su derecho interno cuando los de otro Estado miembro fuesen competentes con arreglo a los foros recogidos en el Reglamento. El presupuesto al que viene supeditada la operatividad de los foros internos es, por lo tanto, que ninguno de los recogidos en el Reglamento atribuya la competencia a los órganos jurisdiccionales de un Estado miembro. Es necesario destacar la

17 Un extenso análisis sobre la descoordinación entre estos reglamentos y la consideración de sus consecuencias en Sánchez Jiménez (2013b: 799). Como indican Quinzá y Gray (2013: 524), la descoordinación no solo se aprecia entre estos Reglamentos, sino que parece un mal endémico que afecta a otros textos. Un análisis de la repercusión de este problema sobre los ciudadanos es realizado por Calvo Caravaca y Carrascosa (2007), Álvarez González (2009: 9) y Fulchiron (2006: 409).

18 Sentencia de 29 de noviembre de 2007, Sundelind López, C-68/07 EU:C:2007:740 —nota a la misma de Garau Sobrino (2007: 763), Quiñones Escámez (2008: 421) y Borrás Rodríguez (2008: 233) —. A sus repercusiones se refiere García López (2009: 307). La evidente necesidad de la interpretación que requerían estos preceptos fue puesta de manifiesto por nuestra parte — Sánchez Jiménez (2004: 741)— con carácter previo a esta sentencia, ahora bien, con una pretensión conciliadora entre ellos, que además es posible, como pudimos reflejar. Es necesario señalar que la operatividad de los foros internos pervive en el nuevo Reglamento (UE) 2019/1111, de modo que cuando derogue el actual RBIIbis, continuarán los problemas que, como ahora se destacan, plantea su aplicación. 
llamativa simplificación en la que el TJUE basa esta solución ${ }^{19}$. Realmente, el supuesto exigía un pronunciamiento expreso sobre la interpretación de la aparente contradicción entre los arts. 6 y 7, pudiendo esperarse que lo hiciera mediante la coordinación de ambos preceptos que, particularmente, exigía la clarificación del objeto del art. 6, dada la confusión derivada de su término «exclusivo». Sin embargo, su opción por la «simplicidad», obviamente más sencilla, implica que su solución va más allá de lo que supone una interpretación del Reglamento ya que, si este recoge dos preceptos, de los que se puede derivar una interpretación conjunta, no se puede comprender que el TJUE considere nula la función de uno de ellos ${ }^{20}$.

En todo caso, esta interpretación del TJUE se identifica con la posible operatividad de los foros internos de los Estados miembros cuando ninguno de los recogidos en el Reglamento pudiera operar en el caso concreto ${ }^{21}$. Siendo este único presupuesto, cualquier foro interno diferente a los recogidos por el RBIIbis puede ser invocado para la atribución de la competencia, incluidos los exorbitantes ${ }^{22}$.

Consideración de los foros internos como vía de solución. Atendiendo al parámetro que marca la operatividad de los foros internos de los Estados miembros (punto de partida), cabe constatar que las «situaciones problemáticas» consideradas en el presente análisis quedan fuera de su alcance. En ellas, como ha quedado descrito, el problema de la denegación de justicia se genera, precisamente, cuando en virtud del RBIIbis la competencia viene atribuida a los órganos jurisdiccionales de un Estado miembro (cuyo ordenamiento no considera válido este matrimonio). La operatividad de los foros del RBIIbis impide la de los foros internos. El resultado, y con él la respuesta a la cuestión planteada al inicio, es la ausencia de solución al problema de la denegación de justicia que, en estos casos, se genera en el propio ámbito comunitario. Un

19 Señala Borrás Rodríguez (2008: 235) que los argumentos no están bien fundados, en lo que tuvo una negativa incidencia el hecho de que no había una opinión emitida por el abogado general.

20 Como señala Garau Sobrino (2007:766), «se trata de una argumentación creativa en contra de la letra del Reglamento mediante la cual el TJCE se convierte en un órgano "creador" del Derecho comunitario".

21 Los foros internos de los Estados miembros que coincidan con alguno de los recogidos por el RBIIbis quedaron «desactivados». Por el contrario, este precepto deja que «sobrevivan», a los efectos de la determinación de la competencia para la disolución del vínculo, los que sean diferentes a los del Reglamento.

22 Una gran amplitud de la operatividad de estos foros, a pesar de la rúbrica del art. 7, cuya referencia a la competencia es «residual», parece mostrar un carácter muy marginal, una aplicabilidad como último resquicio, que no presentan realmente. Con gran amplitud al respecto, Fernández Arroyo (2006: 9). 
resultado que, por ser reflejo de la insuficiencia del mecanismo de los foros internos para abordar este grave problema, se va a constatar siempre, esto es, con independencia de la concreta articulación que, de estos foros, tengan los Estados miembros en sus respectivos ordenamientos internos. La consecuencia es la necesidad de descartar como solución al problema que ahora nos ocupa, la aspiración (en cualquier caso, utópica) de la unificación de estos foros, pues incluso si todos los Estados miembros llegaran a articular en sus normas internas el forum necessitatis, las «situaciones problemáticas» a las que ahora nos referimos no encontrarían solución alguna.

Todo lo anterior constituye la muestra evidente de lo que se ha querido reflejar con el título del presente análisis. Permite constatar que la denegación de justicia que se puede generar en el caso del divorcio entre cónyuges del mismo sexo representa el "paradigma» de la evidente necesidad de articular una solución, que no encuentran en el RBIIbis, y que habría de venir mediante la articulación de un forum necessitatis en este Reglamento. Es más, su trascendencia queda reafirmada si se atiende ahora a la inversa, esto es, a las situaciones en las que los foros internos pudieran ser operativos (caso en que los del RBIIbis no atribuyan competencia a los órganos jurisdiccionales de algún Estado miembro), y ello por un doble argumento. El primero, derivado de una perspectiva comparativa, y el segundo, en atención a los negativos resultados que derivan de la operatividad de los foros internos, frente a los derivados del forum necessitatis que viniera articulado en el reglamento.

Desde un punto de vista comparativo, la relevancia de los resultados se constata atendiendo a la situación, cuando menos paradójica, que resulta al considerar que el problema de denegación de justicia en el caso de divorcio entre cónyuges del mismo sexo no puede encontrar la solución cuando los órganos jurisdiccionales de un Estado miembro fueran competentes en virtud del RBIIbis, frente a la que puede constatarse en caso contrario, es decir, cuando estos foros no atribuyeran competencia a los órganos jurisdiccionales de algún Estado miembro, en el que la posible operatividad de los foros internos podría configurar la vía de solución. Las consecuencias, en atención al caso concreto, pueden constatarse mediante el ejemplo de matrimonio celebrado en España entre varones, siendo uno de ellos nacional español y el otro argentino. En este caso, el lugar de su residencia habitual podría ser determinante de un resultado radicalmente diferente. Si este lugar es un Estado miembro que no admite la validez de este matrimonio (por ejemplo, Italia), no podrían operar los foros internos, en concreto el forum necessitatis recogido en la Ley Orgánica del Poder Judicial (LOPJ) ${ }^{23}$ que, por el contrario, sería operativo

23 Un foro que se introdujo en el ordenamiento español mediante la reforma llevada a cabo por la Ley Orgánica 7/2015, de 21 de julio, por la que se modifica la Ley Orgá- 
cuando tuvieran su residencia en un tercer Estado que no admita la validez de ese matrimonio (como pudiera ser, por ejemplo, Marruecos). Teniendo en cuenta los elementos comunes de ambos supuestos y siendo la diferencia entre ambos el país de la residencia habitual del matrimonio en el momento del divorcio, el ciudadano europeo difícilmente va a entender el distinto resultado, percibiendo como una situación discriminatoria el hecho de que, por tener la residencia en un Estado miembro, el problema para presentar esta demanda no encuentre solución alguna en los propios textos reglamentarios. Esta ausencia de solución puede llevar a impulsar a los cónyuges al forum shopping, que precisamente es lo que pretendía evitar el RRIII ${ }^{24}$. Se trata de la única salida a la que quedan abocados, por lo que tolerarla equivale a un conformismo con la discriminación que entraña el hecho de que tenga que ser empleada esta "estrategia», frente a la necesidad de demandar una expresa solución en el marco del RBIIbis.

En todo caso, el resultado del argumento comparativo que se ha considerado exige una inmediata aclaración. En sentido afirmativo permite reafirmar que el problema de la denegación de justicia en las «situaciones problemáticas»

nica 6/1985, de 1 de julio, del Poder Judicial (BOE, 174, de 22 de julio de 2015). Se recoge en su 22 octies, apdo. tercero, y se trata de un precepto que ha sido objeto de importantes críticas doctrinales, tanto por su técnica legislativa como por su rigidez, que exige una flexibilización en su interpretación. Siguiendo a De Miguel Asensio (2016:158), en sentido literal, viene a exigir la constatación de la declinación de la competencia por todos los órganos jurisdiccionales de los distintos Estados conectados con el supuesto, lo que equivale a entender que su operatividad queda supeditada a la necesidad de interponer la demanda ante cada uno de estos tribunales. En realidad, la reforma de la LOPJ ha suscitado importantes y justificadas críticas doctrinales —Espinar y Paredes (2016:199); Fernández y Sánchez (2018: 106); Garcimartín Alférez (2015)—. Como indica Fernández Rozas (2017: 23), «en España, antes de la reforma de la LOPJ en julio de 2015, el forum necessitatis ya había sido reconocido por algunos tratados bilaterales, así como por la jurisprudencia y por la doctrina españolas, interpretado sobre el derecho constitucional a obtener tutela judicial efectiva del art. $24 \mathrm{CE}$ y del art. $47 \mathrm{CDFUE}$, así como el derecho a un proceso justo del art. $6 \mathrm{CEDH}$. De ello fue expresiva la Sentencia del Tribunal Constitucional no 61/2000, de 13 de marzo".

24 Defendido como un remedio provisional por Álvarez de Toledo Quintana (2013: 205), cuando indica «mucho nos tememos que el remedio provisional va a consistir en elevar las barreras de tolerancia respecto del forum shopping, permitiendo a tales parejas un forum shopping forsystem shopping, que les permita plantear la demanda de separación ante el Estado o alguno de los Estados cuyo sistema conflictual permita resolver la cuestión previa mediante alguna de las técnicas de adaptación, sustitución, trasposición o reconocimiento de situaciones creadas en el extranjero, que haga posible la admisión de la demanda». 
en las que ahora nos centramos precisa de una solución, frente a la ausencia de la misma en el RBIIbis. Ahora bien, ello no implica, en absoluto, que la comparación realizada con los casos en que los foros internos pudieran operar y constituir una posible solución, permita deducir una valoración positiva de esta última vía. Esta comparación, si bien trascendente para constatar el resultado expuesto, no se puede confundir con esta última consideración. Así se puede constatar mediante el segundo de los argumentos que han quedado señalados, como es la consideración de los negativos resultados que se derivan de la operatividad de estos foros que, del mismo modo, permite concluir destacando la trascendencia que presenta la articulación del forum necessitatis en el RBIIbis.

La diversidad entre los foros previstos en las respectivas normativas internas de los Estados miembros es determinante de una disparidad en el tratamiento de las situaciones, cuyos resultados dependen de la posibilidad (o no) de alegar en el supuesto concreto la operatividad de los foros internos de algún Estado miembro, y, en caso afirmativo, del concreto foro interno que pueda operar. La solución a la denegación de justicia en el caso de un divorcio entre cónyuges del mismo sexo cuando estos foros pudieran operar no está garantizada, sino en directa dependencia de las circunstancias del supuesto.

La diversidad de estos foros muestra una disparidad en la aplicación del derecho internacional privado entre los Estados miembros, determinada por la falta de criterio común en la coordinación entre los instrumentos comunitarios y el derecho internacional privado interno, con una importante repercusión en la fragmentación. Se trata de las propias consecuencias que genera la operatividad de los foros internos, en tanto constituye la puerta de entrada a la diversidad y, con ella, una auténtica ruptura de la uniformidad de la aplicación de las normas de competencia en materia de disolución o relajación del vínculo matrimonial. La diversificación que introducen, de la que derivan los diferentes regímenes de competencia judicial internacional, supone la inexistencia de un marco jurídico completo para la delimitación de la competencia entre los Estados miembros. Una fragmentación que, además de mostrarse en absoluta discordia con la uniforme aplicación RBIIbis, supone un incremento de la complejidad de su aplicación, que afecta a la previsibilidad del demandado, así como la negativa incidencia en la claridad normativa, la seguridad jurídica y la coherencia, al venir recogido en un texto que configura unas normas comunes para los Estados miembros, con el objeto de facilitar la libre circulación de decisiones ${ }^{25}$.

25 Las resoluciones fundadas en los foros internos al amparo del art. 7 serán reconocidas en el ámbito comunitario. Las dificultades de articular este precepto con el reconocimiento de decisiones son puestas de relieve por Salerno (2007: 77) y Fallon (2013a: 261). 
Estos efectos perversos de la operatividad de los foros internos reflejan la importancia que presenta la eliminación de esta vía. En su lugar se hace preciso arbitrar un mecanismo con el objetivo específico de abordar los casos de denegación de justicia, y aquí manifiesta su trascendencia la articulación del forum necessitatis en el propio RBIIbis, ya que su aplicación puede abarcar los supuestos comprendidos en la operatividad de los foros internos, que así podrían quedar eliminados ${ }^{26}$.

\section{EL FORUM NECESSITATIS COMO VÍA DE SOLUCIÓN}

La repercusión que tendría la articulación del forum necessitatis en el RBIIbis, como vía de solución al problema de la denegación de justicia, permite aportar otros argumentos que se añaden a los que hasta ahora han quedado expuestos, por los que también se constata su trascendencia.

El alcance del forum necessitatis como respuesta. En relación a las «situaciones problemáticas» que ahora se consideran, la respuesta que este foro ofrece al problema de la denegación de justicia puede identificarse como la solución que se presenta más inmediata, en el sentido de necesaria, en tanto no llegue a materializase la unificación del concepto sobre la "validez del matrimonio» entre los Estados miembros, o se aportara un concepto común, a los efectos de la aplicación de los RBIIbis y RRIII ${ }^{27}$. Ahora bien, la importancia del forum

26 La eliminación de la operatividad de los foros internos mediante la articulación del forum necessitatis es específicamente considerada por Biagioni (2012: 26) y Salerno (2011: 915).

27 En cualquier caso, el legislador comunitario es el responsable, ya que, en definitiva, es precisa la aproximación de las legislaciones. Es necesario por ello descartar que la solución en el contexto de la UE pueda venir por el concepto común que pudiera llegar a aportar el TJUE, ya que su labor no es sustituta de la que ha de realizar el legislador. Aun así, no se puede negar la importancia que puede suponer en esta labor la Sentencia de 5 de junio de 2018, Coman, C-673/16, EU:C:2018:385. Su importancia deriva de las implicaciones o consecuencias jurídicas que pudiera llegar a tener como avance para la igualdad, y con ella para la admisión de los matrimonios entre personas del mismo sexo en aquellos Estados miembros que aún no lo admiten. No obstante, esta sentencia no da ese paso, pues la solución del Tribunal se encuentra dentro de los límites del derecho a la libre circulación de personas. La interpretación del concepto de "cónyuge», que realiza, viene limitada al ámbito de aplicación de la Directiva 2004/38, relativa al derecho de los ciudadanos de la Unión y de los miembros de sus familias a circular y residir libremente en el territorio de los Estados miembros, y no cuestiona la actual libertad de los Estados miembros respecto de la legalización del matrimonio entre personas del mismo sexo. Sobre esta STJUE son destacables los 
necessitatis ante estas situaciones no se puede identificar con el límite del alcance de su trascendencia. De ser así, su articulación no sería necesaria una vez que los distintos Estados miembros reconocieran la validez del matrimonio entre personas del mismo sexo. En este sentido es preciso recordar el carácter instrumental, desde el principio señalado, con el que ahora se abordan estas «situaciones problemáticas», en tanto constituyen la muestra evidente de la necesidad de una solución inmediata a la denegación de justicia. Ahora bien, ello no significa que el problema les pertenezca en exclusividad. La trascendencia del alcance del foro de necesidad sobrepasa la que tiene ante estas situaciones, al abarcar el amplio campo de actuación al que puede extenderse el grave problema de la denegación de justicia al que atiende su propio objetivo.

Este amplio alcance que presenta el forum necessitatis por su directa incidencia en la respuesta a las situaciones de denegación de justicia permite considerar que se trata del mecanismo más adecuado frente a otras posibilidades, en particular la que pudiera venir mediante la incorporación de un nuevo foro de competencia a los siete que contempla el art. 3 del RBIIbis, basado en el criterio del «lugar de celebración del matrimonio»" Es cierto que conseguiría impedir que llegaran a generarse las «situaciones problemáticas», sin embargo, como se acaba de señalar, el problema de la denegación de justicia no es exclusivo de ellas. Se trata por ello de una posibilidad con un alcance limitado. Además, existen otras razones que llevan a descartarla. La primera, por la dificultad de justificar este foro en atención al principio de proximidad como base de la articulación de los foros de este precepto, que ha de quedar reflejada en el momento de la presentación de la demanda. No hay fácil encaje entre el principio de proximidad y este foro de competencia. Otra cosa es que el criterio del «lugar de celebración del matrimonio» pueda permitir apreciar la vinculación «suficiente» que exige uno de los presupuestos del foro de necesidad ${ }^{29}$. Posiblemente la dificultad señalada, unida a las

comentarios de la doctrina, entre otros los realizados por Álvarez González (2018: 1); Guzmán Zapater (2018: 9); Jiménez Blanco (2018); Rojo Torrecilla (2018); Toda Castán (2018:365), y Requena-Casanova (2019).

28 En este sentido, Soto Moya (2013a) analiza las consecuencias derivadas del caso en que el RRIII hubiera recogido, entre las posibilidades que otorga para la elección, la relativa a la ley del lugar de celebración del matrimonio.

29 La «vinculación suficiente», como carácter que ha de apreciarse para la articulación del foro de necesidad, es señalada por Biagioni, (2012: 34). En particular, en el presente trabajo, por las razones que quedan señaladas, se considera la vinculación suficiente del «lugar de celebración del matrimonio» para la articulación del forum necessitatis. 
reticencias de la aceptación de este foro por los Estados miembros ${ }^{30}$, motivó que no fuera incorporado, a pesar de que llegó a plantearse por el Parlamento Europeo en su Resolución de 2008 relativa a la "propuesta RRIII»"

A lo anterior se añade una segunda razón, basada en la discriminación que la inserción de este nuevo foro habría de generar. Es cierto que ninguna solución que se articule como respuesta al problema de denegación de justicia puede impedir el resultado discriminatorio que se aprecia en el caso de divorcio entre cónyuges del mismo sexo, frente a los de distinto sexo. Tampoco la que puede ofrecer el forum necessitatis ya que, mientras los cónyuges de distinto sexo tendrían la posibilidad de elegir el órgano jurisdiccional competente entre las posibilidades que le ofrecieran los foros del art. 3 en el caso concreto, los del mismo sexo únicamente podrían contar con los órganos jurisdiccionales que les pudiera ofrecer el forum necessitatis. Ahora bien, esta discriminación, que siempre existe, se vería acrecentada de añadir el foro del lugar de celebración del matrimonio a los del art. 3 del RBIIbis, ya que, en este caso, los cónyuges de distinto sexo contarían, a efectos de su divorcio, con un nuevo foro de competencia que se añadiría a los siete restantes que recoge aquel precepto.

El forum necessitatis en línea con los actuales textos reglamentarios. Otro argumento que pone de relieve la importancia de articular el forum necessitatis en el RBIIbis deriva de la consideración de los actuales reglamentos (UE) que se ocupan de las normas de derecho internacional privado relativas a las relaciones familiares de carácter internacional. Es significativo que todos ellos lo incorporen en sus normas de competencia. Es más, la necesidad de este foro como vía de solución a las situaciones de denegación de justicia ha sido reconocida frente a la posible operatividad de los foros internos que, expresamente, se ha llegado a descartar en el Reglamento (CE) 4/2009 relativo a las

30 Así puede constatarse atendiendo a los precedentes de este texto, es decir, al Convenio de Bruselas de 1998, y concretamente al Informe Borrás cuando señala que los criterios de competencia que se recogen son los que han encontrado la aprobación por todos los Estados (núm. 30). En este mismo contexto señalaba Pirrung (1998: 633) que la articulación de estos criterios presentaba los rasgos evidentes de su historia, que podía denominarse «d'uncompromis à l'autre»; sin embargo, el resultado final parece aceptable. También a ello se refirió el GEDIP, en su decimotercera reunión, Viena, 1921 septiembre 2003, entendiendo que se trata de un criterio anacrónico que habría de plantear problemas para su aceptación por todos los Estados miembros.

31 El criterio de competencia del lugar de celebración del matrimonio fue introducido por el Parlamento Europeo en su Resolución de 2008 relativa a la "propuesta RRIII» [P6_TA (2008) 0502] (enmienda 11). Se integraba en su art. 3 bis, como un criterio añadido a los que recogía este precepto para basar la elección de los tribunales competentes por acuerdo de los cónyuges (autonomía de la voluntad). 
obligaciones de alimentos ${ }^{32}$. En su considerando 15 señala que «con el fin de preservar los intereses de los acreedores de alimentos y de favorecer una buena administración de justicia en la Unión Europea [...] en adelante, debería excluirse toda remisión a las reglas de competencia del derecho nacional ${ }^{33}$. Significativo interés presenta el rechazo expreso que realiza este Reglamento ya que, del mismo modo que el RBIIbis, deriva del Reglamento Bruselas I. Lo que interesa destacar es que la norma que introducía la operatividad de los foros internos (art. 4 del Reglamento Bruselas $\mathrm{I}^{34}$ ), sobre la que vino basada su consideración en el RBIIbis, queda excluida en el Reglamento 4/2009. En este último se opta, en su art. 7, por la regulación expresa del forum necessitatis $^{35}$. Un foro que, del mismo modo, viene articulado en el art. 11 del

32 Reglamento 4/2009, de 18 de diciembre de 2008, relativo a la competencia, la ley aplicable, el reconocimiento y la ejecución de las resoluciones y la cooperación en materia de obligaciones de alimentos (DO L 7, de 10 enero de 2009).

33 Su importancia en este Reglamento es destacada por Pocar (2009: 12); al respecto indica Borrás (2012: 78) que en los recientes textos en materia de competencia judicial internacional no hay una regla igual a la del art. 7 del RBIIbis.

34 Aun siendo una consideración que, en relación al objeto que ahora se aborda, presenta un carácter marginal, no puede dejar de indicarse que la reforma de este último no ha eliminado completamente la operatividad de los foros internos. Aunque su supresión venía prevista en la Propuesta de Reglamento del Parlamento Europeo y del Consejo relativa a la competencia judicial, el reconocimiento y la ejecución de resoluciones judiciales en materia civil y mercantil [documento $\operatorname{COM}(2010) 748$ (Bruselas) (Versión refundida) $\{$ SEC(2010) 1547\} \{SEC(2010) $1548\}$ ], finalmente no fue plasmada en el Reglamento (UE) 1215/2012 del Parlamento Europeo y del Consejo, de 12 de diciembre de 2012, relativo a la competencia judicial, el reconocimiento y la ejecución de resoluciones judiciales en materia civil y mercantil (DO L 351, de 20 de diciembre de 2012). A la consideración del forum necessitatis en el proceso de revisión se refiere Fernández Rozas (2017: 15), indicando que el resultado regulador fue «mucho menos ambicioso que el contenido en la Propuesta». En este sentido, De Miguel Asensio (2013: 12) considera lamentable que finalmente no quedara incluido en el nuevo Reglamento reformado un foro de necesidad, atenuado en mayor o menor medida, como sugería el art. 26 de la propuesta.

35 Establece este precepto que, «cuando ningún órgano jurisdiccional de un Estado miembro sea competente con arreglo a los artículos 3, 4 y 5, los órganos jurisdiccionales de un Estado miembro podrán, en casos excepcionales, conocer del litigio si un procedimiento no puede razonablemente introducirse o llevarse a cabo o resulta imposible en un Estado tercero con el cual el litigio tiene estrecha relación. El litigio debe guardar una conexión suficiente con el Estado miembro del órgano jurisdiccional que vaya a conocer de él». 
Reglamento (UE)650/2012 relativo a las sucesiones mortis causa ${ }^{36}$, así como, posteriormente, por el Reglamento (UE) relativo a los regímenes económicos matrimoniales y el Reglamento (UE) relativo a los efectos patrimoniales de las uniones registradas, los dos de 24 de junio de $2016^{37}$, que ambos recogen en su art. 11. En todos ellos, como expresamente indican sus considerandos, este foro obedece a la finalidad de remediar, en particular, las situaciones de denegación de justicia ${ }^{38}$.

Este objeto muestra la trascendencia que presenta la articulación de este foro en el RBIIbis, que contribuiría a eliminar la diversidad en la unificación de la normas de competencia en la $\mathrm{UE}^{39}$, por lo que su incorporación no debería plantear problemas para su aceptación por los Estados miembros.

\section{PARÁMETROS PARA LA ARTICULACIÓN DEL FORUM NECESSITATIS EN EL REGLAMENTO BRUSELAS II BIS}

La trascendencia de la incorporación del forum necessitatis al RBIIbis que ha quedado expuesta exige avanzar en la respuesta, que ha de pasar por la

36 Reglamento (UE) 650/2012, relativo a la competencia, la ley aplicable, el reconocimiento y la ejecución de las resoluciones, a la aceptación y la ejecución de los documentos públicos en materia de sucesiones mortis causa y a la creación de un certificado sucesorio europeo (DO L 201, de 27 de julio de 2012).

37 Reglamento (UE) 2016/1103, por el que se establece una cooperación reforzada en el ámbito de la competencia, la ley aplicable, el reconocimiento y la ejecución de resoluciones en materia de regímenes económicos matrimoniales y Reglamento (UE) 2016/1104, por el que se establece una cooperación reforzada en el ámbito de la competencia, la ley aplicable, el reconocimiento y la ejecución de resoluciones en materia de efectos patrimoniales de las uniones registradas (ambos en DO L 183, de 8 de julio de 2016). Estos reglamentos indican, en sus respectivos considerandos (41) y (40), que el forum necessitatis que expresamente recogen tiene como finalidad «remediar, en particular, las situaciones de denegación de justicia».

38 En este sentido vid. el considerando (31) del Reglamento 650/2012, (41) del Reglamento 2016/1103 y (40) del Reglamento 2016/1104.

39 Se puede decir con Fernández Rozas (2017: 13) que «en la Unión Europea, aunque la unificación de las normas relativas al Derecho procesal civil internacional ha sido muy importante, se trata de un proceso inacabado y caracterizado por la coexistencia de diversos regímenes. Esto es particularmente elocuente en la materia del forum necessitatis, que está siendo aceptado en la generalidad de los Reglamentos relativos al DIPr, aunque con alcance diferente, ha quedado fuera del régimen general contenido en el Reglamento Bruselas». 
delimitación de los parámetros a los que ha de ajustarse su articulación. A ello obedece el segundo objetivo del presente análisis, al que se dedica el presente apartado.

\section{ESPECIAL CONSIDERACIÓN DE LOS REGLAMENTOS (UE) 2016/1103 Y 2016/1104}

El objetivo ahora perseguido cuenta con la ventaja de poder considerar, como punto de partida, la línea que ofrecen los reglamentos (UE) que se ocupan de las normas de derecho internacional privado relativas a las relaciones familiares de carácter internacional ${ }^{40}$. Ahora bien, al mismo tiempo, la delimitación de los elementos para la configuración del foro de necesidad en el RBIIbis, ha de tener presente las peculiaridades que, en las situaciones de divorcio, puede presentar el planteamiento de la denegación de justicia en atención a la causa que está en su origen. Precisamente, esta última consideración que atiende a la génesis del problema es la que motiva que, entre los textos reglamentarios señalados, presenten especial interés los recientes reglamentos 2016/1103 y 2016/1104 referidos, respectivamente, a la materia de regímenes económicos matrimoniales y a los efectos patrimoniales de las uniones registradas ${ }^{41}$.

El paralelismo en la "protección de la diversidad» de las legislaciones. El motivo de su especial consideración obedece a la constatación de un evidente paralelismo de la causa generadora del problema de la denegación de justicia en las situaciones a las que responden estos textos, respecto de la que está en la base del divorcio entre cónyuges del mismo sexo. En todos los casos se encuentra en la protección de la diversidad de las legislaciones de los Estados miembros ${ }^{42}$.

A los efectos de constatar el paralelismo señalado el considerando (17) del Reglamento 2016/1104 es particularmente claro cuando señala que «ninguna de las disposiciones del presente Reglamento deberá obligar a los

40 Un modelo, el de estos Reglamentos, que permite considerar definitivamente descartada la propuesta que, en su momento, fue realizada por el Parlamento Europeo en su Resolución de 21 de octubre de 2008 relativa a la "propuesta RRIII» (P6_TA (2008) 0502).

41 Véase la nota núm. 37.

42 Sobre la diversidad que se puede constatar entre las legislaciones de los Estados miembros véanse Soto Moya (2018: 11); González Beilfuss (2011: 183); Rodríguez Pineau (2011: 937); Fontanellas Morell (2012: 257); Fernández Rozas (2016: 1); Marín Corsanau (2017: 419); Vargas Gómez-Urrutia (2017: 313), y Vinaixa Miquel (2017:275). 
Estados miembros cuyo ordenamiento jurídico no contemple la institución de la unión registrada a establecer dicha institución en su Derecho nacional $»^{43}$. Es evidente la similitud que presenta con lo previsto en el art. 13 del RRIII y la protección de las legislaciones que constituye su objeto. A ello se ha de añadir el considerando (21), de ambos reglamentos europeos cuando establece que «el presente Reglamento no debe aplicarse a otras cuestiones preliminares, tales como la existencia, validez o reconocimiento del matrimonio (o de la unión registrada), que están reguladas por los Derechos nacionales de los Estados miembros, incluidas sus normas de Derecho internacional privado». Este paralelismo, que deriva de la protección de la diversidad de las legislaciones de los Estados miembros, implica el de sus resultados, en particular la posibilidad de que se genere el problema de la denegación de justicia. Un problema que, frente a la ausencia de solución en el RBIIbis, es objeto de reglamentación en los textos señalados, motivando la especial atención que merece la consideración de la vía que ofrecen para resolverlo.

El modelo que ofrecen los Reglamentos 2016/1103 y 2016/1104. Es preciso dejar claro desde el principio que, a los efectos que ahora se pretenden, la solución recogida en estos textos se aborda únicamente como «modelo», en el sentido de que se trata de considerar los elementos que pudieran aportar para delimitar los parámetros necesarios con los que puede articularse el forum necessitatis en el RBIIbis. No se pretende, en consecuencia, extrapolar esta solución, lo que, además, tampoco sería posible debido a la directa incidencia del carácter marcadamente patrimonial de su respectivo ámbito material en la configuración de los foros de competencia que articulan y, con ellos, en las soluciones que aportan. Esta delimitación de la perspectiva con la que se aborda la solución que ofrecen, motiva que el objetivo ahora perseguido no se identifique con un análisis exhaustivo de su respectiva reglamentación. Se trata de destacar los elementos que pudieran ser esenciales para la articulación de la solución en el RBIIbis.

En este sentido, el punto de partida exige considerar la ubicación sistemática. La protección de la diversidad de las legislaciones de los Estados miembros en los Reglamentos 2016/1103 y 2016/1104 se aborda en sede de competencia judicial (art. 9, de ambos). A partir de dicha protección, y en

43 Por su parte, el considerando (17) del Reglamento 2016/1103 establece que «el presente Reglamento no define el concepto de "matrimonio", que es definido por el derecho nacional de los Estados miembros. Es cierto que la protección de las legislaciones de los Estados miembros es objeto de protección, como puede constatarse posteriormente, si bien no cabe duda de la mayor claridad que, en este sentido, ofrece el considerando (17) del Reglamento 2016/1104. 
coherencia con ella, por la posible denegación de justicia que de la misma se pudiera generar, articulan la solución. Se trata de una consideración no exenta de trascendencia ya que, al venir de estos textos referidos a los tres sectores del Derecho internacional privado, permite mostrar su diferencia con la configuración aportada por los RBIIbis y RRIII, donde tal protección se materializa en las normas conflictuales de este último (art. 13), sin que el primero aporte solución alguna. En este sentido, el primer elemento a considerar es que la protección de la diversidad de las legislaciones, así como el forum necessitatis, han de abordarse en el RBIIbis.

\section{LA INHIBICIÓN DEL ÓRGANO JURISDICCIONAL COMO CLAVE FUNDAMENTAL DE LA SOLUCIÓN}

El art. 9 de los reglamentos 2016/1103 y 2016/1104, bajo la rúbrica de la "competencia alternativa», aborda el primer paso de la solución, que finaliza con el forum necessitatis recogido en su respectivo art. 11.

Art. 9 y protección de la diversidad. El art. 9 de ambos textos reglamentarios tiene por objeto la protección de la diversidad de las legislaciones de los Estados miembros respecto de la "validez del matrimonio» en el primero, y de la institución de la «unión registrada» en el segundo ${ }^{44}$.

La estructura de este precepto, ubicado inmediatamente después de los foros de competencia, se articula en torno a dos apartados de diferente alcance. Si el primero de ellos configura el eje sobre el que gravita cualquier solución que se pretenda, el segundo aborda la primera de estas soluciones, que, obedeciendo a la rúbrica del precepto, se identifica con la «competencia alternativa».

El primero de sus apartados tiene esencial importancia a los efectos que ahora interesan. En el Reglamento 2016/1103 establece que, «con carácter excepcional, si un órgano jurisdiccional del Estado miembro competente en

44 Este objetivo puede constatarse en el considerando (38) del Reglamento 2016/1103 y en el (36) del Reglamento2016/1104. El primero señala que «los órganos jurisdiccionales de un Estado miembro podrán sostener, con arreglo a su Derecho internacional privado, que el matrimonio en cuestión no puede reconocerse a efectos de los procedimientos relativos al régimen económico matrimonial. En tal caso, podrá ser excepcionalmente necesaria su inhibición con arreglo al presente Reglamento». Por su parte, el considerando (36) del segundo Texto establece que «dado que la institución de la unión registrada no está prevista en todos los Estados miembros, los órganos jurisdiccionales de un Estado miembro cuyo Derecho no prevea la institución de la unión registrada se podrán ver, excepcionalmente, en la necesidad de declinar su competencia en virtud del presente Reglamento». 
virtud de los artículos 4, 5, 6, 7 u 8 considera que en su Derecho internacional privado no está reconocido el matrimonio en cuestión a efectos del procedimiento sobre el régimen económico matrimonial, podrá inhibirse. Si el órgano jurisdiccional decide inhibirse, lo hará sin dilación indebida». De manera similar, si bien con la diferencia que después se constata, el Reglamento 2016/1104 señala en su art. 9.1 que «si el órgano jurisdiccional del Estado miembro competente en virtud de los artículos 4 y 5 y del artículo 6, letras a), b), c) o d), considera que en su Derecho no está reconocida la institución de la unión registrada, podrá inhibirse. Si el órgano jurisdiccional decide inhibirse, lo hará sin dilación indebida».

La trascripción del art. 9.1 de estos reglamentos permite constatar que la protección de las diferencias de las legislaciones de los Estados miembros, que constituye su objeto, la introduce de forma paralela a la posibilidad de inhibición, a la que se refiere la consecuencia jurídica del precepto. Este resultado se constata si se considera, con carácter previo, el ámbito del supuesto de hecho.

En el Reglamento 2016/1103 están comprendidos los casos en que la competencia viniera atribuida, en virtud de sus foros, al órgano jurisdiccional de un Estado miembro cuyo ordenamiento no reconociera el matrimonio en cuestión a efectos del procedimiento sobre el régimen económico matrimonial. Se trata de un supuesto que refleja una evidente similitud con el que se constata en las «situaciones problemáticas» que constituyen nuestro objeto, con la única diferencia de que estas vienen referidas al procedimiento sobre el divorcio.

Por su parte, en el Reglamento 2016/1104 se comprenden los casos en que la competencia viniera atribuida al órgano jurisdiccional de un Estado miembro cuyo ordenamiento no reconociera la institución de la unión registrada. Esta atribución de la competencia ha de constatarse en virtud de la operatividad de los foros que se concretan en el propio precepto. Una precisión que permite comprobar la exclusión, como no podía ser de otra forma, del recogido en la letra e) del art. 6, ya que su atribución de la competencia a los órganos jurisdiccionales del Estado miembro «conforme a cuya ley se haya creado la unión registrada» impide que pueda constatarse el presupuesto que está en la base del supuesto de hecho del precepto.

Tras esta delimitación es preciso destacar que la esencial importancia del art. 9.1 se encuentra en la respuesta basada en la posibilidad de la inhibición de los órganos jurisdiccionales a los que viene referido el supuesto. La protección de las diferencias de las legislaciones que está en su objeto, la introduce, al mismo tiempo que establece la base sobre la que se puede arbitrar la solución al problema de la denegación de justicia que puede generarse como consecuencia de aquellas diferencias. 
En este aspecto, el art. 9. 1 de ambos textos reglamentarios, aun teniendo el mismo objetivo que el art. 13 del RRIII, presenta una diferencia de evidente trascendencia, y es que, en tanto que este último únicamente recoge la consecuencia negativa de la protección de la diversidad de las legislaciones en relación a la "validez del matrimonio" («no quedan obligados a pronunciar una sentencia de divorcio»), aquellos, además, aportan la vía que permite una solución.

La inhibición del órgano jurisdiccional competente cuando considere que el ordenamiento del Estado miembro al que pertenece no reconoce la validez del matrimonio a efectos del procedimiento sobre el régimen económico matrimonial (Reglamento 2016/1103), o la institución de la unión registrada (Reglamento 2016/1104), permite que la denegación de justicia que pueda derivarse de la diversidad de las legislaciones que reconocen y protegen tenga una salida coherente. Si la inhibición «cierra la puerta» de la competencia de este órgano jurisdiccional, paralelamente «se abre» la que permite atribuir la competencia a otro diferente. La inhibición, que ha de realizarse sin dilación indebida, no es una solución en sí misma, pero sí el presupuesto necesario, como base de cualquier solución que finalmente se pueda articular.

De este modo, una vez recogida la inhibición en el primer apartado del art. 9, el segundo introduce una primera solución al problema de la denegación de justicia, mediante la posibilidad de la "competencia alternativa" de los órganos jurisdiccionales de otro Estado miembro. A ella se añade la que le sigue después en el art. 11, mediante el forum necessitatis.

La importancia de la inhibición en el contexto del RBIIbis. La trascendencia expuesta del mecanismo de la inhibición se reproduce en el ámbito del RBIIbis. Se trata del presupuesto previo, sobre el que gravita cualquier solución que pueda articularse al problema de la denegación de justicia generado por la diversidad de las legislaciones de los Estados miembros sobre la validez del matrimonio entre personas del mismo sexo. La atribución de competencia mediante los foros del art. 3 a los órganos jurisdiccionales de un Estado miembro que no admita su validez es, precisamente, el motivo que obstruye cualquier posibilidad de solución, provocando el "callejón sin salida» al que los cónyuges se ven abocados. La inhibición de estos órganos competentes permite despejar cualquier vía para su solución. En particular, su articulación con carácter previo al forum necessitatis es esencial, al ser la vía para permitir la operatividad de este foro que, de otro modo, no sería posible, al no constatarse uno de sus presupuestos (ausencia de órgano jurisdiccional de un Estado miembro que pueda asumir la competencia).

Todo ello permite señalar que el art. 9.1 de los Reglamentos 2016/1103 y 2016/1104 configura un parámetro esencial que exige su consideración en el contexto del RBIIbis. En este sentido, el alcance del supuesto de hecho 
del precepto en el que habría de quedar comprendida la inhibición en el RBIIbis, habría de configurarse con la amplitud que es recogido en el Reglamento 2016/1103, al quedar referido al caso en el que la competencia viniera atribuida por cualquiera de los foros del Reglamento. Concretamente, ha de quedar identificado con el caso en que la competencia venga atribuida por el propio Reglamento a los órganos jurisdiccionales de un Estado miembro que no considere válido el matrimonio de cuyo divorcio se trate. El motivo es el mismo que está en la base del Reglamento 2016/1103, y es que no hay ninguno, de entre los foros del RBIIbis, que impida que llegue a constatarse el presupuesto sobre el que gravita el supuesto de hecho, a diferencia de lo que ocurre en el contexto del art. 9 Reglamento 2016/1104.

La articulación del precepto que ahora se defiende para introducir la inhibición del órgano jurisdiccional competente en los casos señalados, permitiría eliminar el art. 13 del RRIII. La protección de las legislaciones de los Estados miembros más restrictivas, que constituye el objeto de este último, ya estaría contemplada en el primero, en el cual, además, se aporta la base esencial de la posible solución al problema de la denegación de justicia que se pueda generar, frente a la simple referencia a la posibilidad de no tener que «pronunciar una sentencia de divorcio». Esta referencia, además de exigir una concreción, que deja en manos del órgano jurisdiccional competente ${ }^{45}$, no incide en la solución del problema de la denegación de justicia, entre otras razones, porque el lugar para esta solución no es un reglamento regulador de la ley aplicable.

De la inhibición al forum necessitatis. Teniendo en cuenta que el alcance con el que se abordan en el presente análisis las soluciones que ofrecen los reglamentos 2016/1103 y 2016/1104 viene limitado a la posible identificación de los parámetros trasladables al contexto del RBIIbis, es necesario señalar, en sentido negativo, que no es posible considerar, a los efectos que ahora interesan, la solución que recogen aquellos textos en el segundo apartado de su respectivo art. 9, basada en la "competencia alternativa», mediante la que permiten la atribución de la competencia a los órganos jurisdiccionales de otro Estado miembro distinto, sobre la base de otro foro diferente ${ }^{46}$.

45 Señala Álvarez de Toledo Quintana (2013: 167) que este precepto amplía, no restringe, las facultades de la autoridad, ya que la posibilidad de "no pronunciar una sentencia de divorcio", recogida en el art. 13 del RRIII, puede entenderse que acoge a los casos en que el órgano jurisdiccional del Estado miembro competente pueda, según lo que establezca su propio derecho procesal, entrar en el fondo y desestimar la demanda, como acordar su inadmisión, absteniéndose de conocer.

46 Establece el apartado segundo del art. 9 del Reglamento 2016/1103 que «si el órgano jurisdiccional competente en virtud de los artículos 4 o 6 se inhibiera y las partes 
Esta solución ha de quedar descartada en el contexto del RBIIbis. La causa se constata al considerar que la alternatividad ya está presente en los foros de su art. 3 y, por lo tanto, el problema de la denegación de justicia se genera cuando el foro (o, en su caso, los foros) que pueda(n) operar, atribuya(n) la competencia a los órganos jurisdiccionales de un Estado miembro que no reconozca la validez del matrimonio de cuyo divorcio se trate. Por este motivo, la "competencia alternativa» en el ámbito del RBIIbis habría de entenderse equivalente a la posibilidad de elección de foro por el demandante (entre los recogidos en el art. 3) sin necesidad de que el caso hubiera de quedar comprendido en alguno de los criterios sobre los que vienen articulados. Una solución cuyo traslado no es posible al ámbito de este Reglamento, tanto por el rechazo que se viene constatando para la configuración de sus foros sobre la autonomía de la voluntad, como porque, al venir limitada a los casos en que se apreciara la denegación de justicia, podría llevar a una inversión de los términos, de modo que, finalmente, ante estos casos, el demandante tendría una posición mucho más ventajosa que, en aquellos otros, en los que no se generase aquel problema, en los que dicha elección quedaría limitada a los foros en los que quedaran comprendidas las circunstancias del caso.

Todo lo anterior permite concluir señalando que, en el contexto del RBIIbis, la solución para el problema de denegación de justicia exige que, tras el precepto regulador de la inhibición, en los términos que han quedado

acordaran atribuir la competencia a los órganos jurisdiccionales de cualquier otro Estado miembro de conformidad con el artículo 7, la competencia para resolver sobre el régimen económico matrimonial recaerá en los órganos jurisdiccionales de ese Estado miembro. En los demás casos, la competencia para resolver sobre el régimen económico matrimonial recaerá en los órganos jurisdiccionales de cualquier otro Estado miembro en virtud de los artículos 6 u 8, o en los órganos jurisdiccionales del Estado miembro de la celebración del matrimonio». Véase al respecto el considerando (38).

Por su parte, el apdo. segundo del art. 9 del Reglamento 2016/1104 establece que «si el órgano jurisdiccional competente mencionado en el apartado 1 del presente artículo se inhibiera y las partes acordaran atribuir la competencia a los órganos jurisdiccionales de cualquier otro Estado miembro de conformidad con el artículo 7, la competencia para resolver sobre los efectos patrimoniales de la unión registrada recaerá en los órganos jurisdiccionales de ese Estado miembro. En los demás casos, la competencia para resolver sobre los efectos patrimoniales de la unión registrada recaerá en los órganos jurisdiccionales de cualquier otro Estado miembro en virtud de los artículos 6 u 8». Véase al respecto el considerando (36). 
expuestos, se articule el forum necessitatis configurado con arreglo a los presupuestos que son objeto de atención inmediata.

\section{PRESUPUESTOS PARA LA OPERATIVIDAD DEL FORUM NECESSITATIS}

De acuerdo con el hilo conductor del presente análisis, es preciso finalizar abordando la configuración que habría de tener el forum necessitatis en el contexto del RBIIbis a través de los presupuestos necesarios para su operatividad. En este sentido es preciso considerar el art. 11 de los Reglamentos 2016/1103 y 2016/1104, con el objeto de delimitar los posibles parámetros que puedan servir para la articulación de estos presupuestos.

Ausencia de órgano jurisdiccional de un Estado miembro que pueda asumir la competencia. Como mecanismo que tiene la finalidad de remediar las situaciones de denegación de justicia, su operatividad queda supeditada, en primer lugar, a la constatación de la ausencia de competencia de los órganos jurisdiccionales de los Estados miembros.

Este presupuesto se puede apreciar en el art. 11 de aquellos textos reglamentarios y se concreta en la delimitación, con la que comienzan, de los supuestos en los que se puede constatar aquella ausencia de competencia, y por tanto, en los que puede operar el forum necessitatis ${ }^{47}$. Esta delimitación es determinante del alcance de este foro. Estos supuestos vienen recogidos de forma alternativa y siempre sobre la base de una regulación coherente con lo previsto en el respectivo art. 9 de aquellos reglamentos cuyo ámbito ha quedado referido ${ }^{48}$. Concretamente, son dos los supuestos que delimita el art.

47 El considerando (41) del Reglamento 2016/1103 y el considerando (40) del Reglamento 2016/1104 indican, de forma casi idéntica, que «a fin de remediar, en particular, las situaciones de denegación de justicia, el presente Reglamento debe prever también un forum necessitatis que permita a un órgano jurisdiccional de un Estado miembro resolver, con carácter excepcional, sobre (un régimen económico matrimonial) (los efectos patrimoniales de una unión registrada) que tenga una estrecha conexión con un tercer Estado. Uno de esos casos excepcionales podría darse cuando resulte imposible sustanciar un procedimiento en el tercer Estado de que se trate, por ejemplo, debido a una guerra civil, o cuando no quepa esperar razonablemente que (uno de los cónyuges incoe o lleve a cabo un procedimiento en ese Estado) (el miembro de una unión registrada incoe o lleve a cabo un procedimiento en ese Estado). Sin embargo, esta competencia fundada en el forum necessitatis solo podrá ejercerse si el caso tiene una conexión suficiente con el Estado miembro del órgano jurisdiccional que conozca del asunto».

El art. 11 del Reglamento 2016/1104 comienza señalando que «cuando ningún órgano jurisdiccional de un Estado miembro sea competente con arreglo a los artículos 
11 de ambos textos. El primero se identifica con el caso en que ninguno de los foros del Reglamento atribuya la competencia a algún Estado miembro (que ninguno resulte operativo en el caso concreto), y el segundo, con aquel en el que la ausencia de competencia sea consecuencia de la inhibición (de acuerdo con lo establecido en el apdo. primero del art. 9), siempre que ningún otro tribunal hubiera resultado competente (de acuerdo con lo previsto en el apartado segundo del art. 9).

Esta coherencia que puede apreciarse entre la delimitación de estos supuestos, que realizan en su art. 11 y la reglamentación previa del respectivo art. 9, motiva la necesidad de emplear las mismas coordenadas para precisar los casos que respondan a este presupuesto en el ámbito del RBIIbis. Con ello se persigue que el foro de necesidad que se articule en este último pueda ser coherente con el precepto que se ha considerado necesario para recoger el mecanismo de la inhibición, ya que ha seguido los elementos que ofrecen los Reglamentos 2016/1103 y 2016/1104, en su respectivo art. 9.1. Ahora bien, en la medida en que su articulación se ha apartado de este último precepto, también, de forma paralela, y por la misma razón de coherencia, la delimitación de aquellos supuestos ha de apartarse de los recogidos en el art. 11 de estos reglamentos.

Sobre esta base, el forum necessitatis que se incorporase al RBIIbis habría de delimitar los supuestos que reflejan el presupuesto que ahora se aborda, pudiendo identificarse, el primero, con aquel en que ninguno de los foros de sus arts. 3, 4 o 5 atribuyera competencia a algún órgano jurisdiccional de algún Estado miembro, y el segundo, con el caso en que se apreciara la inhibición del órgano jurisdiccional de un Estado miembro que no admitiera la validez del matrimonio, cuya competencia le hubiera sido atribuida por cualquiera de los foros del Reglamento ${ }^{49}$.

El rechazo a la competencia alternativa que recoge el art. 9.2 de los Reglamentos 2016/1103 y 2016/1104 impide que, más allá de los supuestos delimitados, sea considerado el art. 11 de estos reglamentos.

4, 5, 6, 7, 8 o 10 o cuando todos los órganos jurisdiccionales se hayan inhibido con arreglo al artículo 9, y ningún órgano jurisdiccional de un Estado miembro sea competente en virtud del artículo 6, letra e), o de los artículos 7, 8 y 10».

Esta delimitación es la misma que se constata en el art. 11 del Reglamento 2016/1103, lo que obedece a la coincidencia con su art. 9.1 para la delimitación de los supuestos sobre los que gravita la inhibición en el contexto del RBIIbis. Sin embargo, en la medida en que se ha separado de los parámetros empleados por el art. 9.1 del Reglamento 2016/1104, también es preciso que se aparte de la delimitación que realiza el art. 11 de este último, concretamente en el segundo caso en el que se puede constatar la ausencia de competencia que motiva la operatividad del forum necessitatis. 
Imposibilidad o dificultad del desarrollo del proceso en un Estado no miembro $U E$. El forum necessitatis viene también supeditado al requisito de la constatación de la imposibilidad o dificultad para incoarse o desarrollarse el proceso en un Estado no perteneciente a la UE, con el que la situación tuviera una conexión estrecha. El mismo objetivo al que obedece este foro exige, para su operatividad, la constatación de la denegación de justicia generada al no poder delimitarse ningún órgano jurisdiccional competente para la presentación de la demanda. El art. 11 de los Reglamentos 2016/1103 y 2016/1104 vincula su operatividad, siempre excepcional, a la constatación de este presupuesto ${ }^{50}$.

Del mismo modo, habría de ser considerado para la articulación del forum necessitatis del RBIIbis, determinando la necesidad de constatar la imposibilidad o dificultad del desarrollo del proceso de divorcio en el Estado no miembro de la UE que estuviera estrechamente conectado con la situación. Teniendo en cuenta el peso cuantitativo de los países que no admiten el matrimonio entre personas del mismo sexo, en el caso de su divorcio, cabe pensar que no va a ser infrecuente la apreciación de este segundo presupuesto.

Su vinculación a la constatación de la imposibilidad o dificultad para incoarse o desarrollarse el proceso en este Estado con el que se aprecia la conexión, es una condición plenamente coherente con el objetivo de la denegación de justicia al que obedece el forum necessitatis. Su articulación no se realiza para ofrecer un nuevo foro que permita presentar la demanda ante los tribunales de algún Estado miembro cuando se pudiera interponer ante los tribunales de un tercer Estado con el que la situación se vincula.

Este presupuesto adquiere pleno sentido en el primero de los supuestos que han quedado delimitados, es decir, en aquel en que ninguno de los foros de sus arts. 3, 4 o 5 atribuyera competencia a algún órgano jurisdiccional de algún Estado miembro. De no encontrarse el caso en ninguno de los criterios recogidos en estos foros basados en la proximidad, se puede entender que la conexión estrecha la presenta con un Estado no miembro de la UE. Sin embargo, en el segundo de estos supuestos, la inhibición de los órganos jurisdiccionales competentes en virtud de los foros del propio Reglamento ya lleva implícita la imposibilidad del desarrollo del procedimiento de divorcio en el Estado miembro al que dichos órganos pertenezcan, a lo que se añade

50 El respectivo art.11 de ambos reglamentos exige, del mismo modo, que el «proceso no pudiera incoarse o desarrollarse razonablemente o si resultara imposible en un tercer Estado con el que el asunto tuviese una estrecha conexión». También es idéntico el respectivo considerando (41) cuando indica que estos casos pueden apreciarse, "por ejemplo, debido a una guerra civil, o cuando no quepa esperar razonablemente que uno de los cónyuges incoe o lleve a cabo un procedimiento en ese Estado». 
la constatación de la conexión con dicho Estado reflejada la atribución de la competencia a sus órganos jurisdiccionales de acuerdo con el Reglamento.

Conexión suficiente del supuesto con un Estado miembro. Finalmente, el último de los presupuestos para la operatividad del forum necessitatis se identifica con la necesidad de que el asunto tenga una conexión suficiente con el Estado miembro al que pertenece el órgano jurisdiccional al que, por este foro, se le puede atribuir la competencia.

Esta vinculación «suficiente» como presupuesto del forum necessitatis es siempre exigida al ser, precisamente, la que justifica la atribución de competencia a los órganos jurisdiccionales del Estado miembro con el que aquella se aprecie ${ }^{51}$.

Respecto de este presupuesto, con el que, evidentemente, habría de articularse el forum necessitatis en el contexto del RBIIbis, es preciso destacar la trascendencia que presenta el criterio del «lugar de celebración del matrimonio» cuando se identificara en un Estado miembro. La conexión «suficiente» con dicho Estado puede apreciarse porque su ordenamiento, considerado para valorar la existencia del matrimonio, también puede serlo para valorar la relajación o disolución del vínculo matrimonial. Se trata de apreciar la conexión en grado suficiente, lo que es diferente al principio de proximidad que pudiera justificar que este criterio estuviera en la base de un foro de competencia, posibilidad que antes ha quedado descartada.

La consideración del carácter suficiente de la conexión con el Estado miembro de la celebración del matrimonio es esencial en el caso de los matrimonios entre cónyuges del mismo sexo. La invariabilidad de este lugar permite la atribución de competencia a los órganos jurisdiccionales de dicho Estado cuando se constate una modificación de la residencia desde la celebración al momento de la presentación de la demanda. Y ello, con independencia de que esta modificación hubiera sido a un Estado miembro (caso en que encontramos todos los elementos que configuran las «situaciones problemáticas», de esencial consideración en el presente análisis), como a un Estado no miembro. La solución que aporta este foro al problema de la denegación de justicia iguala la respuesta para todos los casos en que se aprecie este problema, evitando la discriminación que actualmente existe mediante la operatividad de los foros internos ${ }^{52}$.

51 Sobre la «vinculación suficiente», como carácter que ha de apreciarse para la articulación del foro de necesidad como muestran los textos comunitarios, véanse Biagioni (2012: 34) y Fallon (2005: 241).

52 Así se puede constatar si se trae a este momento el mismo ejemplo que se expuso en las páginas anteriores para considerar la discriminación que actualmente existe por la 


\section{CONCLUSIONES}

1. La ineludible necesidad de la incorporación del forum necessitatis al RBIIbis que se muestra en el presente trabajo, respondiendo al primero de sus objetivos, se aborda a través del problema de la denegación de justicia que se puede generar en el caso de divorcio entre cónyuges del mismo sexo. La diferencia entre los Estados miembros respecto del concepto de «validez del matrimonio» es la causa del problema que resulta cuando los órganos jurisdiccionales competentes, de acuerdo con el RBIIbis, pertenecen a un Estado miembro que no considere válido el matrimonio entre personas del mismo sexo. Estas son las que se han denominado «situaciones problemáticas», sobre las que se desarrolla el presente análisis, ya que, por su especial gravedad, constituyen el evidente reflejo ("paradigma») de la necesidad, que incluso podría calificarse urgente, de una solución inminente.

No se puede comprender que este problema, que no es nuevo, persista en el tiempo sin que el legislador comunitario haya adoptado medidas concretas para darle una salida. Su evidente pasividad manifiesta una falta de interés o, cuando menos, su opción por el recurso a la "técnica del avestruz», quizá a la espera de que el problema "se» solucione al desaparecer (por sí sola) la causa que lo genera. Una actitud injustificable que, además, es la muestra palpable de su irresponsabilidad, ya que, no se olvide, fue el propio legislador comunitario quien profundizó en la brecha que está en la base del problema, al introducir en el art. 13 del RRIII la protección de la diversidad de las legislaciones de los Estados miembros, que supone la priorización de la concepción más restrictiva sobre el concepto de "validez del matrimonio».

Siendo evidente la necesaria unificación de este concepto en su más amplia acepción, lo cierto es que, en tanto exista la diversidad, también persisten sus negativas consecuencias, que son evidentes en las «situaciones problemáticas» que ahora se abordan. La denegación de justicia que se genera y, con ella, la vulneración del derecho a la tutela judicial en el espacio judicial de libertad

operatividad de los foros internos (apartado II, 2), referido al matrimonio celebrado en España entre varones, siendo uno de ellos nacional español y el otro argentino. En este caso, llegado el momento de su divorcio, la operatividad del forum necessitatis puede aportar la solución al problema de la denegación de justicia que se pudiera generar, tanto si hubieran modificado su residencia a un Estado miembro que no admite la validez de dicho matrimonio (en el ejemplo, Italia), como si la tuvieran trasladado a un Estado no miembro (como Marruecos). No obstante, si en el primer caso la solución viene condicionada a la inhibición previa de los tribunales competentes en virtud del Reglamento (italianos), en el segundo adquiere todo el sentido el segundo presupuesto al que viene condicionada la operatividad del foro de necesidad. 
y seguridad europeo, determinan la indudable responsabilidad de afrontarlas y de arbitrar una solución, que ha de venir en el RBIIbis, como texto regulador de la competencia, mediante la articulación del forum necessitatis. Su incuestionable trascendencia, patente en su propio objetivo de responder a la denegación de justicia, se incrementa en atención a la amplitud de su repercusión, que va más allá de las situaciones sobre las que gravita este análisis. La incorporación de este foro aportaría una solución acorde con la uniformidad que es necesaria en un texto reglamentario, frente a la única e insuficiente vía que ofrece el RBIIbis mediante la operatividad de los foros internos que en sus arts. 6 y 7 recoge.

2. La insuficiencia de esta vía es evidente ante las situaciones en las que este análisis ha centrado su desarrollo, a las que no ofrece solución alguna. En atención al parámetro que permite la operatividad de los foros internos (sentencia Sundelind), estas situaciones siempre quedan fuera del alcance de esta vía, como consecuencia de que, en ellas, la competencia viene atribuida por el RBIIbis a los órganos jurisdiccionales de un Estado miembro (cuyo ordenamiento no admite la validez del matrimonio entre personas del mismo sexo). La ausencia de solución al problema de la denegación de justicia es el resultado que confirma la necesidad de una respuesta en el propio reglamento mediante el forum necessitatis. Es más, la trascendencia de la incorporación de este foro también se pone de manifiesto más allá de estas situaciones, es decir, si se consideran aquellas otras en las que, en efecto, pudieran operar los foros internos. La respuesta que esta vía puede ofrecer como solución al problema de la denegación de justicia refleja sus efectos negativos como consecuencia de la diferente articulación de estos foros por los Estados miembros. Su operatividad constituye la puerta de entrada a la diversidad y, con ella, a la disparidad del tratamiento de idénticas situaciones, que conlleva una auténtica ruptura de la uniformidad de la aplicación de las normas de competencia en materia de disolución o relajación del vínculo matrimonial. La respuesta que pueden ofrecer depende, primero, de las circunstancias del supuesto, determinantes del Estado miembro cuyos foros internos se puedan alegar, y segundo, de los concretos foros que este Estado tenga articulados en su ordenamiento interno, que condicionan, en última instancia, la posible solución.

El panorama «cargado de nubarrones» que ofrece esta vía, muestra la trascendencia que habría de presentar la articulación del forum necessitatis en el propio reglamento. Su objeto específico de abordar los casos de denegación de justicia permite abarcar los supuestos en que esta se plantee, incluidos los que están en la base de la operatividad de los foros internos, motivando la posibilidad de su eliminación.

Junto a las anteriores razones, la trascendencia expuesta también se constata en atención a los posteriores reglamentos (UE) que se ocupan de las 
normas de derecho internacional privado relativas a las relaciones familiares de carácter internacional. Es, cuando menos, llamativo que en todos ellos se encuentra articulado el forum necessitatis y en ninguno la vía de la operatividad de los foros internos, justo a la inversa de lo que ocurre en el RBIIbis, cuyas normas de competencia relativas al divorcio, separación judicial y nulidad matrimonial han permanecido prácticamente invariables desde el texto en el que tuvo su origen. Esta inamovilidad exige un cambio para su adaptación a la evolución de las soluciones que se refleja en aquellos reglamentos y que, al introducirlas, muestran que en la actualidad son las que se consideran más acertadas.

3. La incorporación del forum necessitatis al RBIIbis, en línea con estos textos reglamentarios, no debería plantear problemas de aceptación por los Estados miembros. Además, la solución que aportan estos reglamentos ofrece la posibilidad de su consideración, como punto de partida, para la articulación del forum necessitatis en el contexto del RBIIbis. A ello obedece el segundo objetivo del presente análisis, que si bien es cierto que cuenta con la ventaja de poder partir de aquellas soluciones, también es verdad que su desarrollo ha de tener presente las peculiaridades que, en las situaciones de divorcio, puede presentar el planteamiento del problema de la denegación de justicia en atención a la causa que está en su origen. Y es precisamente esta consideración la que motiva que, entre los textos reglamentarios, presenten especial interés los recientes reglamentos de la UE, como son el Reglamento 2016/1103, en materia de regímenes económicos matrimoniales, y el Reglamento 2016/1104, sobre los efectos patrimoniales de las uniones registradas. La razón se encuentra en el paralelismo entre el planteamiento del problema de la denegación de justicia que puede generarse en las materias a las que dichos textos se refieren y la que se plantea ante la situación de divorcio entre cónyuges del mismo sexo, ya que comparten su causa, que se encuentra en la diversidad de las legislaciones de los Estados miembros y la ausencia de un concepto común, ya sea respecto a la «validez del matrimonio» o a la «unión registrada». Una diversidad que, además, es objeto de protección en todos estos reglamentos.

Este paralelismo en el planteamiento del problema motiva que la solución articulada en los Reglamentos 2016/1103 y 2016/1104, de forma muy similar, sea objeto de especial atención, si bien en ningún caso con la finalidad de extrapolar los preceptos en los que se recoge al contexto del RBIIbis, imposible entre otras razones. Su consideración tiene sentido a los efectos de delimitar los posibles elementos que podrían constituir los parámetros para abordar la respuesta en el ámbito de este último.

4. Sobre esta base se aborda la solución que aportan aquellos reglamentos, que gravita sobre dos pilares esenciales, plasmados, respectiva- 
mente, en sus arts. 9 y 11. El primero de ellos introduce la protección de la diversidad de las legislaciones de los Estados miembros. Se refiere al caso en que en el Estado miembro al que pertenece el órgano jurisdiccional competente en virtud de los foros del propio Reglamento no estuviera reconocido el matrimonio en cuestión a efectos del procedimiento sobre el régimen económico matrimonial (Reglamento 2016/1103), o la institución de la unión registrada (Reglamento 2016/1104). La importancia de este precepto radica en establecer, paralelamente, la posible inhibición de este órgano jurisdiccional. Se trata de la clave esencial, al ser la que permite desbloquear el camino para que pueda operar cualquier solución al problema de la denegación de justicia generado como consecuencia de aquellas diferencias y la protección que de las mismas realiza. Este es el motivo de que estos reglamentos, primero, introduzcan el mecanismo de la inhibición (apartado primero de su respectivo art. 9), y posteriormente, aborden la solución al problema.

La importancia de este esquema motiva que se considere en el presente análisis como un parámetro fundamental en el contexto RBIIbis, en el que, del mismo modo, se reproduce la trascendencia de esta respuesta. La solución al problema de la denegación de justicia generado cuando el Estado miembro al que pertenece el órgano jurisdiccional competente para el divorcio no admita la validez del matrimonio en cuestión no puede abordarse sin esta previa inhibición. La atribución de la competencia por el propio reglamento a los órganos jurisdiccionales de un Estado miembro obstruye cualquier vía de solución. Mientras estos no se inhiban, no puede operar el foro de necesidad, al no constatarse uno de sus presupuestos (ausencia de órgano jurisdiccional de un Estado miembro que pueda asumir la competencia). Esta inhibición es, en definitiva, la vía necesaria que ha de existir con carácter previo a la solución con la que el problema puede, finalmente, encontrar el desenlace.

5. Esta definitiva solución se identifica en el presente trabajo con el forum necessitatis. Su finalidad misma de atender a los casos de denegación de justicia exige su incorporación al RBIIbis. Las situaciones a las que este foro habría de dar respuesta ponen de manifiesto que van más allá de las que configuran el objeto de este trabajo, lo que implica que el forum necessitatis seguirá siendo necesario incluso en el caso en que llegara a desaparecer la causa que origina el problema de la denegación de justicia en los casos de divorcio entre cónyuges del mismo sexo, es decir, aun llegado el momento en el que todos los Estados miembros admitieran la validez de este matrimonio.

La delimitación de los elementos con los que puede ser articulado este foro en el contexto del RBIIbis ha de realizarse, por coherencia, de acuerdo con los parámetros que aporta el respectivo art. 11 de los Reglamentos 
2016/1103 y 2016/1104, esencialmente en lo que respecta a la concreción del presupuesto al que, en primer lugar, ha de quedar supeditado que, como mecanismo que tiene el objetivo de remediar las situaciones de denegación de justicia, se identifica con la constatación de la ausencia de competencia de los órganos jurisdiccionales de los Estados miembros. En este sentido, la articulación del forum necessitatis en el RBIIbis exige la consideración de los dos supuestos en los que se constata este presupuesto. Primero, el caso en que ninguno de los foros del Reglamento atribuya la competencia a algún Estado miembro, y segundo, el que deriva de la inhibición de los órganos jurisdiccionales competentes en virtud del Reglamento, cuando pertenezcan a un Estado miembro que no reconozca la validez del matrimonio entre cónyuges del mismo sexo.

La operatividad de este foro viene también supeditada, por su mismo objetivo, al presupuesto de la imposibilidad o dificultad para que el proceso pueda incoarse o desarrollarse en un tercer Estado con el que la situación tuviera una conexión estrecha, al que se añade, por último, la necesidad de que el asunto tenga una conexión suficiente con el Estado miembro al que pertenece el órgano jurisdiccional al que, por este foro, se le podría atribuir la competencia. La consideración de la existencia de tal vinculación con el Estado miembro de la celebración del matrimonio presenta esencial importancia para la definitiva solución al problema de la denegación de justicia en el caso del divorcio entre cónyuges del mismo sexo.

6. Sobre la base de todo lo anterior, y como corolario del presente análisis, se considera que, aunque arriesgada, es oportuna la elaboración de una propuesta del precepto que podría articularse en el RBIIbis, cuya redacción podría quedar del siguiente modo:

El órgano jurisdiccional del Estado miembro competente en virtud de los artículos 3, 4 o 5 podrá inhibirse cuando entendiera que su derecho no considera válido el matrimonio en cuestión a efectos de un procedimiento de divorcio. Si el órgano jurisdiccional decide inhibirse, lo hará sin dilación indebida.

Cuando ningún órgano jurisdiccional de un Estado miembro sea competente con arreglo a los artículos 3, 4 o 5, o cuando el órgano jurisdiccional competente en virtud de estos preceptos se hubiera inhibido de acuerdo con lo previsto en el apartado anterior, los órganos jurisdiccionales de un Estado miembro, podrán resolver sobre la nulidad, separación o divorcio si el proceso no pudiere incoarse o desarrollarse razonablemente o si resultare imposible en un tercer Estado con el cual el asunto tuviese una conexión estrecha. El asunto deberá tener una conexión suficiente con el Estado miembro del órgano jurisdiccional que conozca de él. 
7. Finalmente, no es posible finalizar sin lamentar que cualquier esfuerzo por aportar una solución al problema que a lo largo del presente trabajo se ha considerado no parece que sea del interés del legislador comunitario. Muestra de ello es que el nuevo Reglamento (UE) 2019/1111, de 25 de junio de 2019 (DOUE L. 178 de 2 de julio de 2019), se ha centrado en la modificación de los aspectos relativos a la responsabilidad parental (y sustracción internacional de menores). Es destacable la muy escasa, casi nula, alteración de las normas de competencia en materia de nulidad, separación judicial y divorcio que introduce el nuevo Reglamento y que serán operativas a partir del 1 de agosto de 2022, fecha en la que quedará derogado el RBIIbis. Se habrá perdido una nueva oportunidad para abordar la modificación de estos foros y, en particular, y por lo que ahora interesa, para introducir el forum necessitatis. El nuevo Reglamento 2019/1111 seguirá siendo el único que no lo articula, de entre los que se refieren a las materias relativas a las relaciones familiares de carácter internacional, así como el único que recoge la operatividad de los foros internos, con la que continúa. Aunque el legislador comunitario pretenda acostumbrarnos a esta inamovilidad, es preciso continuar poniendo de manifiesto que la necesidad de evolución es una cuestión de responsabilidad, por su directa repercusión en el ciudadano europeo.

\section{Bibliografía}

Abarca Junco, A. P. (2013). Algunos problemas en el ámbito de aplicación del Reglamento Roma III. En J. Forner Delaygua, C. González Beilfuss y R. Viñas Farré (coords). Entre Bruselas y La Haya. Estudios sobre la unificación internacional y regional del Derecho internacional privado. Liber Amicorum Alegría Borrás (pp. 45-58). Madrid: Marcial Pons.

Álvarez de Toledo Quintana, L. (2013). La cuestión previa de la «existencia de matrimonio» en el proceso de divorcio con elemento extranjero. Cuadernos de Derecho Transnacional, 5 (2), 140-208.

Álvarez González, S. (2007). Matrimonio entre personas del mismo sexo y doctrina de la DGRN: una lectura más crítica. Diario La Ley, 28 (6629), 1531-1538.

(2009). Dimensión internacional del matrimonio entre personas del mismo sexo: lo que el ojo del legislador español no vio. En S. Álvarez González, M. P. García Rubio y M. Requejo Isidro (coords.). Estudios de derecho de familia y de sucesiones (dimensiones interna e internacional) (pp. 9-38). Santiago de Compostela: Universidad de Santiago de Compostela.

- (2018). ¿ ¿Matrimonio entre personas del mismo sexo para toda la UE?: A propósito de las conclusiones del Abogado General en el Asunto Coman. La Ley Unión Europea, 56, 1. 
Arenas García, R. (2004). Crisis matrimoniales internacionales. Nulidad matrimonial, separación y divorcio en el nuevo Derecho internacional privado español. Santiago de Compostela: Universidad de Santiago de Compostela.

- (2005). La doctrina reciente de la DGRN en materia de celebración del matrimonio en los supuestos internacionales. Anuario Español de Derecho Internacional Privado, 5, 351-372.

Biagioni, G. (2012). Alcuni caratteri generali del forum necessitatis nello spazio giudiziario europeo. Cuadernos de Derecho Transnacional, 4 (1), 20-36.

Borrás Rodríguez, A. (2008). "Exclusive" and "Residual" Grounds of Jurisdiction on Divorce in The Brussels II bis Regulation (zuEuGH, 29.11.2007 -Rs.C-68/07 -Sundelind Lopez/Lopez Lizazo, unten S. 257, Nr.12). IPrax, Praxis des Internationalen Privat- und Verfahrensrechts, 3, 233-243.

(2012). La diversificación de las fuentes y su interrelación en el Derecho Internacional Privado de la Unión Europea y de sus Estados Miembros. En A. Borrás y G. Garriga (eds.). Adaptación de la Legislación interna a la normativa de la Unión Europea en materia de cooperación civil. Homenaje al Prof. Dr. Ramón Viñas Farré (pp. 51-79). Madrid: Marcial Pons.

(2013). Introduction Générale. En S. Corneloup (dir). Droit Européen du divorce. European divorce law (pp. 4-11). Dijon: Université de Bourgogne.

Calvo Caravaca, A. L. y Carrascosa J. (2007). Los matrimonios entre personas del mismo sexo en la Unión Europea. Revista Crítica de Derecho Inmobiliario, 700, 443-475.

Corneloup, S. (2013). Article 1. Champ d'application (Commentarie du Règlement 1259/2010 Rome III). En S. Corneloup (dir). Droit Européen du divorce. European divorce law (pp. 493-515). Dijon: Université de Bourgogne.

De Miguel Asensio, P. (2013). El nuevo Reglamento sobre competencia judicial y reconocimiento y ejecución de resoluciones. Diario La Ley, 8013, 1-4.

(2016). Ley de la jurisdicción voluntaria y Derecho internacional privado. Anuario Español de Derecho Internacional Privado, 16, 147-197.

Devers, A. y Farge, M. (2012). Le nouveau droit international privé du divorce. À propos du règlement Rome III sur la loi applicable au divorce. Droit de la Famille, 6, 1-3.

Diago Diago, M. P. (2007). Matrimonio entre personas del mismo sexo: perspectiva internacional privatista. Estudios de Derecho Judicial, 130, 245-310.

Díaz Fraile, J. M. (2006). Exégesis de la doctrina de la Dirección General de los Registros y del Notariado sobre la reforma del Código civil en materia de matrimonio introducida por la Ley 13/2005, de 1 de julio. Diario La Ley, 6450, $1-12$.

Espinar Vicente, J. M. y Paredes Pérez, I. (2016). Análisis y valoración crítica de la regulación de la sumisión a la jurisdicción española antes y después de la reforma de la ley orgánica del poder judicial (LO 7/2015). Anuario Español de Derecho Internacional Privado, 16, 199-227. 
Esteban de la Rosa, G. (2009). El método del reconocimiento como propuesta de regulación de las nuevas situaciones internacionales vinculadas con la inmigración. Revista de Estudios Jurídicos, 9, 201-234.

Fallon, M. (2005). Le principe de proximité dans le droit de l'Union européenne. En M. N. Jobard-Bachelier y P. Mayer. Le Droit international privé: esprit et méthodes. Mélanges en l'honneur de P. Lagarde (pp. 241-262). Paris: Dalloz.

(2013). Article 6. Caractère exclusif des compétences établies aux articles 3, 4 et 5, en (Commentarie des dispositions du Règlement 2201/2003 Bruxelles II bis relatives au divorce). En S. Corneloup (dir). Droit Européen du divorce. European divorce law (pp. 261-272). Dijon: Université de Bourgogne.

Fernández Arroyo, D. P. (2006). Compétence exclusive et compétence exorbitante dans les relations privées internationales. Recueil des Cours Académie de Droit International, 323, 9-250.

Fernández Rozas, J. C. (2016). Un hito más en la comunitarización del Derecho internacional privado: regímenes económicos matrimoniales y efectos patrimoniales de las uniones registradas. La Ley Unión Europea, 4 (40), 1-29.

— (2017). Rigidez versus flexibilidad en la ordenación de la competencia judicial internacional: el forumnecessitatis. En V. M. Rojas Amandi (coord.). Desarrollos Modernos del Derecho Internacional Privado. Libro Homenaje al Dr. Leonel Pereznieto Castro (pp. 229-285). México: Tirant lo Blanch.

Fernández Rozas, J. C. y Sánchez Lorenzo, S. (2018). Derecho internacional privado. Madrid: Civitas-Thomson Reuters.

Fontanellas Morell, J. M. (2012). Una primera lectura de las propuestas de reglamento comunitario en materia de regímenes económico matrimoniales y de efectos patrimoniales de las uniones registradas. En C. Parra (dir.). Nuevos reglamentos comunitarios y su impacto en el derecho catalán (pp. 257-290). Barcelona: Bosch.

Franzina, P. (2011). The law applicable to divorce and legal separation under regulation (EU) No. 1259/2010 of 20 december 2010. Cuadernos de Derecho Transnacional, 3 (2), 85-129.

Fulchiron, H. (2006). Mariage et partenariats homosexuels en droit international prive francais. Revue de Droit International de Droit Comparé, 2, 409-438. Disponible en: https://doi.org/10.3406/ridc.2006.19430.

Garau Sobrino, F. (2007). Nota a la Sentencia Tribunal de Justicia de las Comunidades Europeas (Sala Tercera), de 29 de noviembre de 2007, en el asunto C-68/07 (Sundelind López). Revista Española de Derecho Internacional, 59 (2), 763-766.

García López, J. A. (2009). Repercusiones de la Sentencia del Tribunal de Justicia Europeo en el asunto «Sundelind López»: ámbito de aplicación espacial a las normas de competencia judicial internacional de la Unión Europea en materia de separación y divorcio. Anuario Español de Derecho Internacional Privado, 9, 307-325. 
García Rubio, M. P. (2005). La modificación del Código Civil en materia de derecho a contraer matrimonio. Diario La Ley, 6359, 1-11.

Garcimartín Alférez, F. J. (2015). La competencia judicial internacional en la reforma de la Ley Orgánica del Poder Judicial. Diario La Ley, 8614, 1-11.

González Beilfuss, C. (2004a). Parejas de hecho y matrimonios del mismo sexo en la Unión Europea. Madrid: Marcial Pons.

- (2004b). Relaciones e interacciones entre Derecho comunitario, Derecho internacional privado y Derecho de familia europeo en la construcción de un espacio judicial común. Anuario Español de Derecho Internacional Privado, 4, 117-190.

— (2011). The Proposal for a Council Regulation on the Property Consequences of Registered Partnerships. Yearbook of Private International Law, 183-198.

Gruber, U. P. (2013). Le mariage homosexuel et le droit international privé allemand. Revue Critique de Droit International Privé, 102 (1), 65-73.

Guzmán Zapater, M. (2012). Divorcio, matrimonio y ciertas diferencias nacionales: a propósito de su tratamiento en el artículo 13 del Reglamento Roma III. En C. Espulgues Mota y G. Palao Moreno (eds). Nuevas Fronteras del Derecho de la Unión Europea. Liber Amicorum José Luis Iglesias Buhigues (pp. 521-536). Valencia: Tirant lo Blanch.

- (2018). Matrimonio entre personas del mismo sexo y Derecho a la Libertad de Circulación (sobre la STJ, Gran Sala, 5 de junio de 2018, en el AS. C-673/16, Coman). Revista Electrónica de Estudios Internacionales, 36, 9-16.

Hammje, P. (2011). Le nouveau règlement (UE) n. ${ }^{\circ}$ 1259/2010 du Conseil du 20 décembre 2010 mettant en œuvre une coopération renforcée dans le domaine de la loi applicable au divorce et à la séparation de corps. Revue Critique de Droit International Privé, 100 (2), 291-338.

Jiménez Blanco, P. (2018). La movilidad transfronteriza de matrimonios entre personas del mismo sexo: la UE da un paso. Sentencia del Tribunal de Justicia de 5 de junio de 2018, asunto C-673/16: Coman. La Ley Unión Europea, 61, $1-12$.

Joubert, N. (2013). Article 13. Différences dans le droit national (Commentaire du Règlement 1259/2010 Rome III). En S. Corneloup (dir). Droit Européen du divorce. European divorce law (pp. 624-638). Dijon: Université de Bourgogne.

Marín Corsanau, D. (2017). Las «uniones registradas» en España como beneficiarias del derecho de la UE a propósito de la Directiva 2004/38/CE y del Reglamento (UE) 2016/1104. Cuadernos de Derecho Transnacional, 9 (2), 419-447. Disponible en: https://doi.org/10.20318/cdt.2017.3880.

Maseda Rodríguez, J. (2018). Matrimonio entre personas del mismo sexo y Reglamento 2201/2003 regulador de la competencia judicial internacional en materia de separación judicial y/o divorcio: inclusión o exclusión. Revista Ius et Praxis, 24 (1), 207-242. Disponible en: https://doi.org/10.4067/S071800122018000100207.

Mosconi, F. (2005). Le nuove tipologie di convivenza nel diritto europeo e comunitario. Rivista di Diritto Internazionale Privato e Processuale, 305-314. 
Orejudo Prieto de Los Mozos, P. (2002). La celebración y el reconocimiento de la validez del matrimonio en Derecho Internacional Privado español. Madrid: Aranzadi.

- (2006). Private International Law problems relating to celebration of same-sex mariages: DGRN of 29 july 2005. Yearbook of Private International Law, 8, 299-306.

- (2012). La nueva regulación de la ley aplicable a la separación judicial y al divorcio: aplicación del Reglamento Roma III en España. Diario La Ley, 7913, $1-14$.

Pirrung, J. (1998). Unification du droit en matière familiale: la Convention de l'Union européenne sur la reconnaissance des divorces et la question de nouveaux travaux d'Unidroit. Uniform Law Review, 3, 629-640. Disponible en: https://doi.org/10.1093/ulr/3.2-3.629.

Pocar, F. (2009). La disciplina comunitaria della giurisdizione in tema di alimenti: il Regolamento 4/2009. En M. C. Baruffi y R. Cafari Panico (eds.). Le nuove competenze comunitarie. Obbligazioni alimentari e successioni (pp. 3-16). Padova: Casa Editrice Dott. Antonio Milani.

Quinzá Redondo, P. y Gray, J. (2013). La (des)coordinación entre la propuesta de Reglamento de Régimen Económico Matrimonial y los Reglamentos en materia de Divorcio y Sucesiones. Anuario Español de Derecho Internacional Privado, 13, 513-542.

Quiñones Escámez, A. (2005). Límites a la celebración en España de matrimonios internacionales del mismo sexo. Revista Jurídica de Cataluña, 104 (4), 11711190.

- (2008). ¿Cuándo se aplica el Reglamento Bruselas II bis? El TJCE se pronuncia sobre su ámbito de aplicación. Revista de Derecho Comunitario Europeo, 12 (30), 457-482.

Requena-Casanova, M. (2019). Libre circulación de los matrimonios del mismo sexo celebrados en el territorio de la Unión Europea: consecuencias del asunto Coman y otros. Revista de Derecho Comunitario Europeo, 23 (62), 41-79. Disponible en: https://doi.org/10.18042/cepc/rdce.62.02.

Rigaux, F. (2000). The Law Applicable to Non Traditional Families. En J. Basedow, I. Meier, A. K. Schnyder, T. Einhorn y D. Girsberger (eds.). Private Law in the International Arena. From National Conflict Rules towards Harmonization and Unification. Liber Amicorum Kurt Siehr (pp. 647-656). The Hague: T. M. C. Asser Press.

Rodríguez Pineau, E. (2011). Los efectos patrimoniales de las uniones registradas: algunas consideraciones sobre la propuesta de Reglamento del Consejo. Anuario Español de Derecho Internacional Privado, 11, 937-955.

Rodríguez Vázquez, M. A. (2008). Los matrimonios entre personas del mismo sexo en el Derecho internacional privado español. Boletín Mexicano de Derecho Comparado, 122, 913-941. 
Rojo Torrecilla, E. (2018). ¿Ampliación o reinterpretación del concepto de cónyuge en el Derecho de la UE? Su impacto sobre el derecho de residencia y libre circulación. Notas a la STJUE de 5 de julio 2018. El Blog de Eduardo Rojo [blog]. Disponible en: https://bit.ly/2JjU849.

Salerno, F. (2007). I criteri di giurisdizione comunitari in materia matrimoniale. Rivista di Diritto Internazionale Privato e Processuale, 63-82.

- (2011). Competenza giurisdizionale, riconosciment delle decisioni e diritto al giusto proceso nella prospettiva europea. Rivista di Diritto Internazionale Privato e Processuale, 47 (4), 895-938.

Sánchez Jiménez, M. A. (2004). Carácter exclusivo de los foros del Reglamento 1347/2000. La oscura redacción de sus artículos 7 y 8. En A. L. Calvo Caravaca y E. Castellanos (coords.). El Derecho de Familia ante el siglo XXI. Aspectos internacionales (pp. 741-774). La Coruña: Editorial Constitución y Leyes.

- (2013a). El divorcio internacional en la Unión Europea (Jurisdicción y Ley aplicable). Madrid: Thomson Reuters-Aranzadi.

- (2013b). Reglamentación comunitaria relativa a las crisis matrimoniales y la particular «crisis» de los Reglamentos que la integran. En J. J. Forner Delaygua, C. González Beilfuss y R. Viñas Farré (coords). Entre Bruselas y La Haya. Estudios sobre la unificación internacional y regional del Derecho internacional privado. Liber Amicorum Alegría Borrás (pp. 799-820). Madrid: Marcial Pons.

Soto Moya, M. (2013a). Uniones transfronterizas entre personas del mismo sexo. Valencia: Tirant Lo Blanch.

(2013b). La aplicación de los Reglamentos 2201/2003 (Bruselas II bis) y 1259/2010 (Roma III) a los matrimonios del mismo sexo. En E. M. Vázquez Gómez, M. D. Adam Muñoz y N. Cornago Prieto. El arreglo pacífico de controversias internacionales: XXIV Jornadas de la Asociación española de profesores de derecho internacional y relaciones internacionales. Córdoba, 20-22 de octubre de 2011 (pp. 595-606). Valencia: Tirant Lo Blanch.

— (2018). El reglamento (UE) 2016/1104 sobre régimen patrimonial de las parejas registradas: algunas cuestiones controvertidas de su puesta en funcionamiento en el sistema español de derecho internacional privado. Revista Electrónica de Estudios Internacionales, 1-32. Disponible en: https://doi.org/10.17103/ reei.35.03.

Toda Castán, D. (2018). Límites de la ciudadanía de la Unión como motor de los derechos fundamentales: comentario a la Sentencia Coman del Tribunal de Justicia. Revista General de Derecho Europeo, 46, 365-393.

Vargas Gómez-Urrutia, M. (2017). El puzle se complica. Efectos patrimoniales de las uniones registradas y Reglamento (UE) 2016/1104. Problemas de calificación y coordinación entre los instrumentos europeos conexos. En M. Guzmán Zapater y C. Esplugues Mota (dirs.). Persona y familia en el nuevo modelo español de Derecho internacional privado (pp. 313-329). Valencia: Tirant lo Blanch. 
Vinaixa Miquel, M. (2017). La autonomía de la voluntad en los recientes Reglamentos UE en materia de regímenes económicos matrimoniales (2016/1103) y efectos patrimoniales de las uniones registradas (2016/1104). Indret, 2, 274-313.

Zabalo Escudero, E. y Diago Diago, P. (2007). Matrimonio entre personas del mismo sexo: perspectiva internacional privatista. Estudios de Derecho Judicial, 130, 245-310. 